\title{
Integrating CVMix into GOTM (v6.0): a consistent framework for testing, comparing, and applying ocean mixing schemes
}

\author{
Qing Li ${ }^{1}$, Jorn Bruggeman ${ }^{2,3}$, Hans Burchard ${ }^{4}$, Knut Klingbeil ${ }^{4}$, Lars Umlauf ${ }^{4}$, and Karsten Bolding ${ }^{2,5}$ \\ ${ }^{1}$ Fluid Dynamics and Solid Mechanics, Los Alamos National Laboratory, Los Alamos, NM, USA \\ ${ }^{2}$ Bolding \& Bruggeman ApS., Asperup, Denmark \\ ${ }^{3}$ Plymouth Marine Laboratory, Prospect Place, the Hoe, Plymouth, UK \\ ${ }^{4}$ Leibniz Institute for Baltic Sea Research Warnemünde, Rostock, Germany \\ ${ }^{5}$ Department of Bioscience, Aarhus University, Silkeborg, Denmark
}

Correspondence: Qing Li (qingli@lanl.gov)

Received: 23 December 2020 - Discussion started: 17 February 2021

Revised: 4 June 2021 - Accepted: 11 June 2021 - Published: 6 July 2021

\begin{abstract}
The General Ocean Turbulence Model (GOTM) is a one-dimensional water column model, including a set of state-of-the-art turbulence closure models, and has widely been used in various applications in the ocean modeling community. Here, we extend GOTM to include a set of newly developed ocean surface vertical mixing parameterizations of Langmuir turbulence via coupling with the Community Vertical Mixing Project (CVMix). A Stokes drift module is also implemented in GOTM to provide the necessary ocean surface waves information to the Langmuir turbulence parameterizations, as well as to facilitate future development and evaluation of new Langmuir turbulence parameterizations. In addition, a streamlined workflow with Python and Jupyter notebooks is also described, enabled by the newly developed and more flexible configuration capability of GOTM. The newly implemented Langmuir turbulence parameterizations are evaluated against theoretical scalings and available observations in four test cases, including an idealized wind-driven entrainment case and three realistic cases at Ocean Station Papa, the northern North Sea, and the central Baltic Sea, and compared with the existing general length scale scheme in GOTM. The results are consistent with previous studies. This development extends the capability of GOTM towards including the effects of ocean surface waves and provides useful toolsets for the ocean modeling community to further study the effects of Langmuir turbulence in a broader scope.
\end{abstract}

\section{Introduction}

The parameterization of vertical turbulent transport in the ocean surface boundary layer (OSBL) is an essential component of an ocean general circulation model (OGCM), representing the effects of unresolved small-scale boundary layer turbulence on redistributing heat, momentum, and trace gases within the OSBL and mediating the exchange of these quantities between the atmosphere and the ocean interior. Li et al. (2019) compared a set of OSBL turbulent mixing parameterizations under idealized and realistic conditions, with a focus on those that include the effects of Langmuir turbulence. Significant discrepancies were found among many OSBL parameterizations, both with and without Langmuir turbulence, highlighting the uncertainties in our understanding of the physical processes in the OSBL and the necessity of future development of a better OSBL turbulent mixing parameterization. While the comparison across many OSBL parameterizations in Li et al. (2019) provides useful insights into the relative importance of various different physical processes and forcings, a careful evaluation against observations is useful to assess the quantitative performance of these OSBL parameterizations.

The General Ocean Turbulence Model (GOTM; Burchard et al., 1999; Umlauf and Burchard, 2005; Umlauf et al., 2014, see updated version on https://gotm.net/, last access: 1 July 2021) is a one-dimensional water column model including a library of state-of-the-art turbulence closure models. It has been used, for example, to understand the evolution of 
thermal stratification in the North Sea and the northern Pacific (Burchard and Bolding, 2001), effects of breaking surface waves on surface boundary layer dynamics (see, e.g., Jones and Monismith, 2008), entrainment into bottom gravity currents (Arneborg et al., 2007), mixing in sloping bottom boundary layers (Umlauf and Burchard, 2010; Umlauf et al., 2015), and sediment dynamics (see, e.g., Conley et al., 2008; Burchard et al., 2013). Since GOTM has been coupled to biogeochemical models (Burchard et al., 2006; Bruggeman and Bolding, 2014), it has been used for several studies of marine ecosystems (see, e.g., Steiner et al., 2007; Hense and Quack, 2009; van der Molen et al., 2013; Kerimoglu et al., 2017; Powley et al., 2020). Furthermore, GOTM provides a useful platform both to compare across many OSBL parameterizations (e.g., Burchard and Bolding, 2001; Li et al., 2019) and to evaluate them against observations (e.g., Burchard et al., 2008). The turbulence module of GOTM has been integrated into several OGCMs, either by directly linking it as a module or by recoding; see, e.g., the General Estuarine Transport Model (GETM, Burchard and Bolding, 2002), the Regional Ocean Modelling System (ROMS, Haidvogel et al., 2000), the Nucleus for European Modelling of the Ocean (NEMO, Madec et al., 1991), the Semi-implicit Cross-scale Hydroscience Integrated System Model (SCHISM, Zhang et al., 2016), the Finite Volume Community Ocean Model (FVCOM, Chen et al., 2003) and the Proudman Oceanographic Laboratory Coastal Ocean Modelling System (POLCOMS, Holt and Umlauf, 2008).

The work of Li et al. (2019) assembles a set of new OSBL parameterizations with Langmuir turbulence using GOTM as the common driver. To make it available as part of a community model, a consistent implementation of the underlying algorithms has been made. A more general use of these OSBL parameterizations, e.g., in an OGCM, requires proper integration into the existing GOTM code. This paper documents the implementation of many functionalities described in Li et al. (2019) into the main GOTM repository by reimplementing some of the OSBL parameterizations in a way that is consistent with the existing GOTM code, promoting the coupling of the turbulence module to OGCMs. In particular, the efforts of incorporating the Community Vertical Mixing Project (CVMix, Griffies et al., 2015) in GOTM is described, which enables the $K$-profile parameterization (KPP, Large et al., 1994), as well as a few KPP variants that include the effects of Langmuir turbulence (e.g., Li et al., 2016; Reichl et al., 2016; Li and Fox-Kemper, 2017). A new Stokes drift module is also implemented in GOTM to facilitate the development and evaluation of Langmuir turbulence parameterizations in GOTM. While we are aware that Langmuir parameterizations have also been developed for secondmoment turbulence models (e.g., Axell, 2002; Kantha and Clayson, 2004; Harcourt, 2013, 2015), we will implement and test these schemes in GOTM at a later point. The primary goal of this work is to extend the capability of GOTM, both as an ocean turbulence closure library and as a stand-alone one-dimensional water column model, to enable systematic comparison across many different parameterizations within a common framework. This will allow us to precisely separate differences induced by variations in the turbulence parameterizations from those associated with different numerical schemes, parameterizations of the ocean surface fluxes, and other secondary effects.

In addition to documenting the implementation of CVMix in GOTM and the updates to improve the user interface, this paper also evaluates these new OSBL parameterizations in GOTM against available observations at a few sites. In particular, we focus on the influence of Langmuir turbulence in such evaluations, which has never been done in GOTM.

The remainder of this paper is organized as follows. Development of incorporating CVMix and a Stokes drift module in GOTM is described in Sect. 2, together with an introduction of a streamlined workflow with Python (https: //www.python.org, last access: 1 July 2021) and Jupyter notebook (https://jupyter.org, last access: 1 July 2021) enabled by the newly developed and more flexible configuration capability in GOTM. Evaluation against available theories and observations in four test cases is presented in Sect. 3. This paper ends with a brief discussion and main conclusions in Sect. 4.

\section{Extending the functionality of GOTM}

\subsection{CVMix in GOTM}

CVMix (Griffies et al., 2015) is a portable vertical mixing software package providing an extensible framework for the development of first-order turbulence closures. It provides a set of subroutines allowing flexible implementation of surface and interior turbulence closures in KPP (Large et al., 1994; Van Roekel et al., 2018) in an ocean general circulation model (OGCM). These subroutines can be assembled in different ways to accommodate different needs (e.g., loop structure, available mean field variables) of the host OGCMs. Recently, a few Langmuir turbulence parameterization schemes based on KPP have also been included in CVMix (e.g., Li et al., 2016; Reichl et al., 2016; Li and Fox-Kemper, 2017). This allows easy implementations and testing of these Langmuir turbulence parameterization schemes in other models.

The General Ocean Turbulence Model (GOTM, Umlauf and Burchard, 2005; Umlauf et al., 2014, see updated version on https://gotm.net/, last access: 1 July 2021) provides a collection of various turbulence closure schemes for the vertical mixing in the ocean and lakes, in particular secondorder turbulence closures. The procedures and variables representing the implementation of these models are encapsulated in GOTM's FORTRAN module turbulence as illustrated in Fig. 1. This module can be easily integrated in any existing library structure of a third-party OGCM or lake model. In addition, GOTM can also be used as a stand-alone 
one-dimensional water column model with flexible configurations to study the hydrodynamic and thermodynamic processes related to vertical mixing in natural waters. In this case, the turbulence routines are called from inside GOTM's main time loop implemented in the central FORTRAN module gotm (see Fig. 1). For these reasons, GOTM provides a useful platform for developing and comparing different ocean and lake vertical mixing parameterizations in both idealized and realistic scenarios (e.g., Burchard and Bolding, 2001; Umlauf and Burchard, 2005; Burchard et al., 2008; Li et al., 2019).

As a first step towards extending the capability of GOTM to include Langmuir turbulence parameterizations, CVMix is incorporated in GOTM as an external library, including the above-mentioned first-order closure models of Langmuir turbulence based on KPP (see Fig. 1). Methodically, this is similar to the approach taken in Li et al. (2019) that enables the cross-comparison among a set of Langmuir turbulence parameterization schemes in the single-column setup. Here, a user interface is developed and described that ensures consistency with the other modules of the GOTM code, such as the mean flow and the meteorological forcing modules (interface module gotm_cvmix; see Fig. 1). Variables passed to CVMix through this interface module include mean flow variables such as the currents, temperature and salinity, surface forcing variables such as the surface friction velocity and surface buoyancy flux, and wave forcing variables such as the Langmuir number and Langmuir enhancement factor. In return, turbulence variables such as the turbulent diffusivity and viscosity are passed back to the GOTM main time loop.

Using the new interface to CVMix, it is now possible to directly call the CVMix subroutines, thereby making a range of recent Langmuir turbulence parameterizations directly available in GOTM, and in OGCMs or lake models that use GOTM. This allows to objectively compare stateof-the-art versions of the KPP model and second-moment closure models. Note that the CVMix interface is separate from the GOTM turbulence module (Fig. 1), so additional modifications to the source code of the host model are still needed. However, such modifications are significantly less than would be needed if CVMix were to be directly implemented in the host model.

\subsection{Stokes drift in GOTM}

Stokes drift (see a recent review by van den Bremer and Breivik, 2018, and references therein) is a key property of ocean surface waves that is crucial for the dynamics and parameterizations of Langmuir turbulence (e.g., McWilliams et al., 1997; Li et al., 2019). To provide the necessary information of the Stokes drift for various Langmuir turbulence parameterizations, Stokes drift variables and a few options to configure the Stokes drift are implemented as a new module in GOTM. These different options of Stokes drift provide a way to test the sensitivity of a Langmuir parameterization to the uncertainties in the estimate of Stokes drift.

The most flexible option is to directly read in the Stokes drift profiles from a file (see FORTRAN module stokes_drift in Fig. 1). The Stokes drift profiles can be either computed from the wave spectrum of direct measurements and wave models, or estimated from some empirical relations. Tools for generating the Stokes drift input file for GOTM from various sources are provided on GitHub (https://github.com/qingli411/gotmtool, last access: 1 July 2021). To assist the development and testing of Langmuir turbulence parameterizations, two idealized options are also implemented (Fig. 1). The first option assumes a monochromatic surface wave, for which the Stokes drift is an exponentially decaying profile with depth defined by the surface value $\boldsymbol{u}_{0}^{\mathrm{S}}$ and a decay depth scale $\delta^{\mathrm{S}}$ :

$\boldsymbol{u}^{\mathrm{S}}(z)=\boldsymbol{u}_{0}^{\mathrm{S}} \exp \left(\frac{z}{\delta^{\mathrm{S}}}\right)$

where $z \leq 0$ is the water depth. The exponential profiles have been used in many idealized large eddy simulations of Langmuir turbulence (e.g., McWilliams et al., 1997; Grant and Belcher, 2009). The second option assumes a Stokes drift profile that depends only on the wind, derived from a set of empirical relations and assumptions (the "theory wave" approach of Li et al., 2017; see their Eq. 25). This "theory wave" approach estimates the Stokes drift profile from the wind assuming a $f^{-5}$ (where $f$ is the frequency) spectral shape (sea also Breivik et al., 2016) with the directional spread correction of Webb and Fox-Kemper (2015). The surface value and integrated transport of Stokes drift are estimated using empirical relations. By estimating the Stokes drift from the local wind, the contribution of swell is not explicitly represented, except a constant magnitude loss coefficient tuned against a WAVEWATCH III global wave hindcast simulation to represent the reduction effect by swell (Webb and Fox-Kemper, 2015). It has been shown to provide enough information of the ocean surface waves to allow a reasonable representation of the effects of Langmuir turbulence in OGCMs without coupling with a wave model through either a KPP variant (Li et al., 2017) or an energeticsbased planetary boundary layer scheme (Reichl and Hallberg, 2018; Reichl and Li, 2019). For both the exponential and the "theory wave" options, the controlling parameters (surface value and decay depth of Stokes drift in the former case and surface wind in the latter) can be set to constant or read from a file.

It should be noted that in this study the Stokes drift profile is only used in the Langmuir turbulence parameterizations without being integrated into the mean flow module in GOTM (e.g., Coriolis-Stokes force). This is consistent with the requirement of the two KPP-based Langmuir turbulence parameterizations used here. For other Langmuir turbulence parameterizations, direct modifications of the mean flow equations in GOTM due to Stokes drift may be nec- 


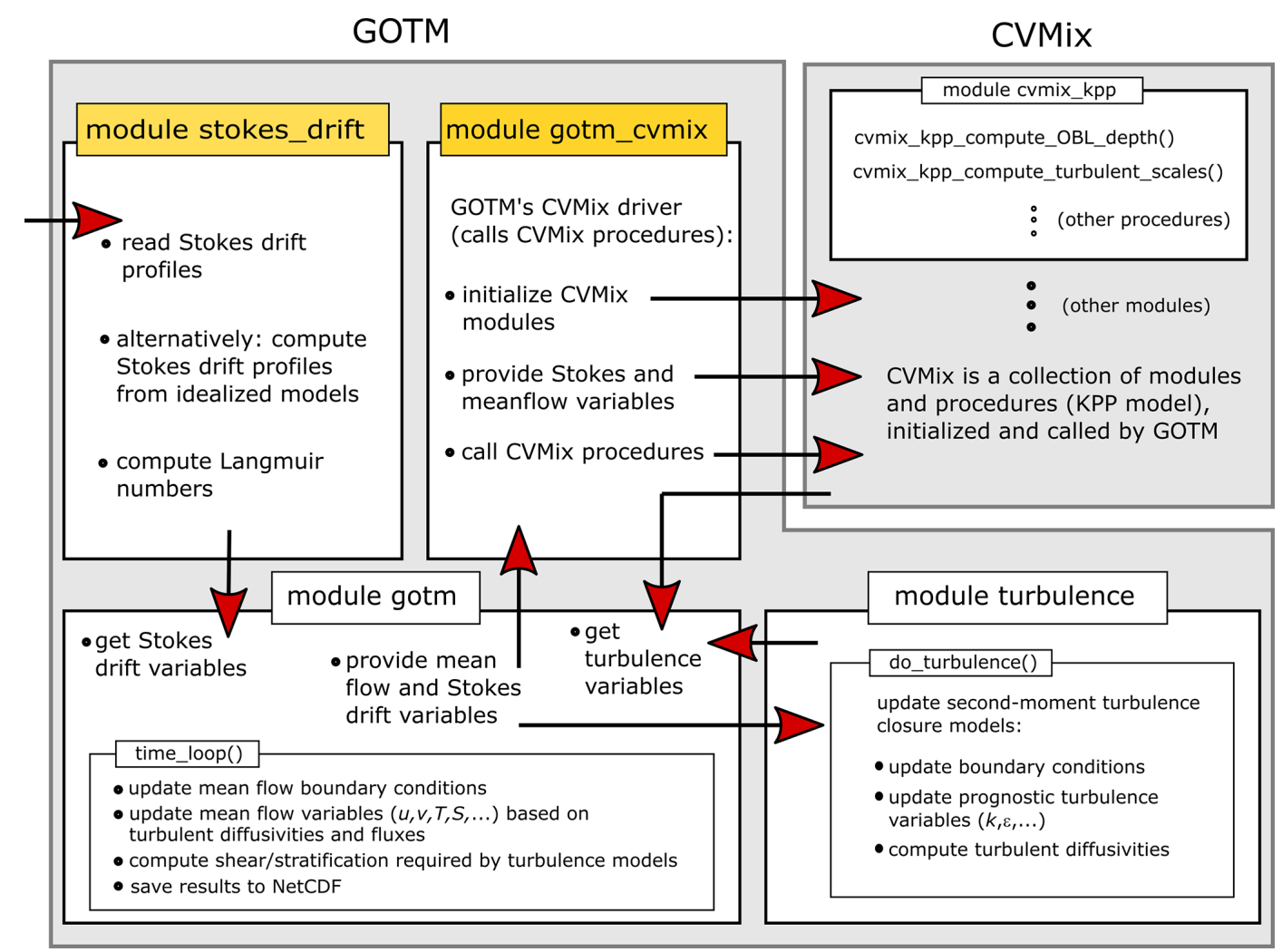

Figure 1. Schematic diagram illustrating the coupling of GOTM and CVMix. New GOTM modules are highlighted in yellow; interfaces between different model components are indicated as red arrows. Note that, for clarity, only a selection of the most relevant modules, procedures, and interfaces is shown.

essary (see, e.g., Appendix A of Li et al., 2019), which is straightforward as the full Stokes drift is now readily available in GOTM.

\subsection{A streamlined workflow in GOTM}

GOTM now supports the human-readable data-serialization language YAML (https://yaml.org/, last access: 1 July 2021) for the configuration of parameters. YAML is both more user-friendly and more developer-friendly than the FORTRAN namelist originally used in GOTM for the configuration. It has a clean and minimal syntax and is easy for extension and maintenance. The default values and the documentation of the configuration parameters of GOTM are now stored in the source code, so that the configurations can be generated from the compiled GOTM executable. This eliminates the need to save the default values of configuration parameters in a separate file, e.g., an XML file (https: //www.w3.org/TR/xml11/, last access: 1 July 2021, as previously used in GOTM as well as many other ocean models. This is a useful feature especially for the development and maintenance of GOTM, since the configurations are always consistent with the source code. For GOTM users, this also guarantees that a compatible configuration file is always available whenever the source code is updated, which would require extra efforts if FORTRAN namelist files were used.

Taking advantage of this new feature of GOTM, a Python (https://www.python.org, last access: 1 July 2021) wrapper of GOTM (i.e., an interface to access GOTM in Python) for easily working with GOTM in the Jupyter notebook (https: //jupyter.org, last access: 1 July 2021) environment was also developed. After an initial setup step in the terminal, everything from building the GOTM executable, configuring the parameters, running GOTM simulations, to visualizing the simulation results can now be performed in the Jupyter notebook environment. The source code and some examples are publicly available on GitHub (https://github.com/qingli411/ gotmtool, last access: 1 July 2021). The Jupyter notebooks to run the test cases and plot all the figures in this paper are available on GitHub (https://github.com/qingli411/A2020_ CVMix_in_GOTM, last access: 1 July 2021) for maximum reproducibility. They also serve as additional examples of using these tools.

\section{Evaluation}

We evaluate the newly implemented CVMix and Stokes drift modules in GOTM in three configurations: (i) KPP-CVMix: 
a typical KPP configuration with key parameters summarized in Table 1; (ii) KPPLT-VR12: a variant of KPP to account for the Langmuir-turbulence-enhanced mixing (Li et al., 2016); (iii) KPPLT-LF17: a variant of KPP to additionally account for the Langmuir-turbulence-induced entrainment ( $\mathrm{Li}$ and Fox-Kemper, 2017). The KPP parameters in Table 1 are default values in CVMix, which are described in more detail in Griffies et al. (2015). The sensitivity of KPP to different choices of these parameters is beyond the scope of this study (see, e.g., Van Roekel et al., 2018) but can be easily explored with this new framework. See Appendix A1 of Li et al. (2019) for a more detailed description of KPPLT-VR12 and KPPLT-LF17.

The generic length scale (GLS, Umlauf and Burchard, 2003) scheme in the $k-\varepsilon$ formulation with the weakequilibrium stability function by Canuto et al. (2001), using a steady-state Richardson number of $R i_{\text {st }}=0.25$, denoted as GLS-C01A hereafter, is used as a reference. The parameters used in GLS-C01A are summarized in Table 2.

In the following sections, GOTM simulations with the above four vertical mixing schemes will be compared with available theoretical scalings or observations in four different test cases. We use a Cartesian coordinate system with $x$ and $y$ denoting the horizontal coordinates, $z$ the vertical (upward) coordinate, and $u, v$, and $w$ the corresponding components of the velocity.

\subsection{Idealized entrainment}

The first test case is an idealized wind stress-driven entrainment case with no rotation, in which the OSBL gradually entrains into an underlying non-turbulent region with constant stable stratification. The GOTM simulation results can be directly compared with the relation derived from laboratory experiments (e.g., Price, 1979), in which the time evolution of the mixed layer depth $h_{\mathrm{m}}$ follows

$h_{\mathrm{m}}(t)=\left(2 R_{v}\right)^{1 / 4} u_{*}\left(\frac{t}{N_{0}}\right)^{1 / 2}$,

where $R_{v} \approx 0.6$ is the bulk Richardson number, $u_{*}$ the water side surface friction velocity, and $N_{0}$ the initial buoyancy frequency. See further discussion on this relation and the model configuration in Umlauf and Burchard (2005).

We run the idealized entrainment case in GOTM for $30 \mathrm{~h}$ on a vertical domain of $50 \mathrm{~m}$ with 250 equally spaced layers and a time step of $6 \mathrm{~s}$. Here, we are using a relatively high vertical resolution and short time step to better capture the time evolution of the mixed layer. See Sect. 3.5 for a discussion of the sensitivity of the four vertical mixing schemes to the vertical resolution and time step. The surface friction velocity is $u_{*}=0.01 \mathrm{~m} \mathrm{~s}^{-1}$ and the initial buoyancy frequency is $N_{0}=0.01 \mathrm{~s}^{-1}$. Earth's rotation is not considered.

To test the effect of parameterizing the Langmuirturbulence-enhanced mixing and the Langmuir-turbulenceenhanced entrainment in KPPLT-VR12 and KPPLT-LF17, we assume a Stokes drift in the wind direction (here in the $x$ direction) that exponentially decays with depth following Eq. (1), with a surface value of $u_{0}^{\mathrm{S}}=\left|\boldsymbol{u}_{0}^{\mathrm{S}}\right|=0.11 \mathrm{~m} \mathrm{~s}^{-1}$ and decay scale of $\delta^{S}=5 \mathrm{~m}$. This corresponds to a turbulent Langmuir number,

$L a_{\mathrm{t}}=\left(\frac{u_{*}}{u_{0}^{\mathrm{S}}}\right)^{1 / 2} \approx 0.3$,

at which Langmuir turbulence has a prominent influence on the turbulent mixing in the mixed layer (McWilliams et al., 1997).

Figure 2 compares the vertical profiles of the velocity, $u$, turbulent viscosity, $v_{m}$, and squared buoyancy frequency, $N^{2}$, in all the four vertical mixing schemes at the end of the $30 \mathrm{~h}$ simulations. KPP-CVMix predicts higher turbulent viscosity than GLS-C01A, and the resulting velocity profile is more well mixed in the mixed layer. KPPLT-VR12 accounts for Langmuir-enhanced mixing by enhancing the turbulent viscosity in KPP-CVMix. The resulting velocity profile is more well mixed than KPP-CVMix. KPPLT-LF17 additionally accounts entrainment due to Langmuir turbulence which makes the mixed layer deeper. The turbulent viscosity is similar to KPPLT-VR12. These results are consistent with the design of KPPLT-VR12 and KPPLT-LF17. The strikingly smaller $N^{2}$ in the entrainment layer in GLS-C01A (panel c) is due to the downward diffusion of turbulent kinetic energy (TKE) into this layer, which is ignored in KPP.

Figure 3 compares the time evolution of the mixed layer depth (MLD) in the four vertical mixing schemes with Eq. (2). Here, the MLD is defined as the depth at which the squared buoyancy flux $N^{2}$ reaches its maximum (see Fig. 2c). An alternative definition based on a TKE threshold of $10^{-6} \mathrm{~m}^{2} \mathrm{~s}^{-2}$ as in Umlauf and Burchard (2005) yields similar results. Consistent with Umlauf and Burchard (2005), GLS-C01A matches the empirical law of the entrainment in Eq. (2) with excellent accuracy. The three KPP variants all overpredict the rate of deepening of the MLD at the beginning of the simulation and underpredict it at later times. As expected, KPPLT-LF17 predicts a deeper mixed layer depth than KPP-CVMix and KPPLT-VR12. Somewhat counterintuitively, KPPLT-VR12 predicts a very similar, or even slightly shallower, MLD as compared to KPP-CVMix in this case. This is because in KPPLT-VR12, the turbulent viscosity is enhanced and the down-wind velocity within the mixed layer is more well mixed and has weaker shear than in KPPCVMix (Fig. 2). Since the boundary layer depth in KPP is determined by the depth at which the bulk Richardson number first reaches a critical number ( 0.3 here), and the resolved shear term dominates the denominator of the bulk Richardson number (see Eq. 21 of Large et al., 1994) in this case, the reduced velocity shear in KPPLT-VR12 results in a slightly bigger bulk Richardson number and therefore a slightly shallower boundary layer depth than that in KPP-CVMix. This undesirable behavior of KPPLT-VR12 was one of the moti- 
Table 1. Summary of parameters and settings in KPP-CVMix.

\begin{tabular}{lll}
\hline Description & CVMix parameter & Value/reference \\
\hline Critical Richardson number & Ri_crit & 0.3 \\
Nondimensional extent of surface layer & surf_layer_ext & 0.1 \\
Matching method between the OSBL and interior & MatchTechnique & 'SimpleShapes' \\
Interpolation type for the bulk Richardson number & interp_type & 'quadratic' \\
Interpolation type for the diffusivity and viscosity & interp_type2 & 'LMD94' \\
Enhance diffusivity at OSBL & lenhanced_diff & .true. \\
Limit the OSBL by the Ekman depth & lEkman & . false. \\
Limit the OSBL by the Monin-Obukhov length & lMonOb & . false. \\
Zero gradient of the shape function at OSBL & lnoDGat1 & .true. \\
$C_{v}$ for the unresolved shear & CV & Eq. (A3) of Danabasoglu et al. (2006) \\
Entrainment layer stratification & - & Eq. (39) of Van Roekel et al. (2018) \\
\hline
\end{tabular}

Note that we are focusing on the OSBL mixing in KPP, and the interior mixing in CVMix is disabled here. OSBL: ocean surface boundary layer.

Table 2. Summary of the generic length scale parameters in GLS-C01A.

\begin{tabular}{rrrrrrrrrrr}
\hline & $m$ & $n$ & $p$ & $c_{1}$ & $c_{2}$ & $c_{3}^{-}$ & $c_{3}^{+}$ & $\sigma_{k}$ & $\sigma_{\psi}$ & $R i_{\text {st }}$ \\
\hline GLS-C01A & 1.5 & -1.0 & 3.0 & 1.44 & 1.92 & $-0.62^{*}$ & 1.0 & 1.0 & 1.3 & 0.25 \\
\hline
\end{tabular}

* Value computed from the steady-state Richardson number $R i_{\mathrm{st}}$. See, e.g., Umlauf and Burchard (2003).

vations to further include the Langmuir-turbulence-enhanced entrainment in KPPLT-LF17 (Li and Fox-Kemper, 2017).

\subsection{Ocean Station Papa}

The meteorological and oceanic observations at Ocean Station Papa (OSPapa; 50.1 ${ }^{\circ} \mathrm{N}, 144.9^{\circ} \mathrm{W}$; https://www.pmel. noaa.gov/ocs/Papa, last access: 1 July 2021) have been used to evaluate the performance of OSBL turbulent mixing schemes in many studies (e.g., Martin, 1985; Large et al., 1994; Kantha and Clayson, 1994; D'Alessio et al., 1998; Burchard and Bolding, 2001; Acreman and Jeffery, 2007), focusing mostly on the year 1961. Recent measurements of ocean surface waves at OSPapa (Thomson et al., 2013) allow us to evaluate the effects of Langmuir turbulence parameterizations and assess the importance of Langmuir turbulence at this site.

Here, we use the temperature and salinity mooring data at OSPapa to initialize the GOTM simulations from rest in a $150 \mathrm{~m}$ vertical domain with 150 vertical grid cells. The time step is $60 \mathrm{~s}$. Surface boundary conditions are set by the hourly surface flux data from 21 March 2012 to 20 March 2013. Throughout the year, Jerlov water type II (Paulson and Simpson, 1977) is assumed. Half-hourly wave spectral data collected using the Datawell Waverider buoy (http://cdip.ucsd. edu/metadata/166p1, last access: 1 July 2021), and binned into $n=64$ frequency bands with $f_{1}=0.025 \mathrm{~Hz}$ and $f_{64}=$ $0.58 \mathrm{~Hz}$, are used to estimate the Stokes drift for the Langmuir turbulence parameterizations. The Stokes drift profile is estimated from the band wave energy density spectrum $S_{i}$ according to

$\boldsymbol{u}^{\mathrm{S}}(z)=\frac{16 \pi^{3}}{g} \sum_{i=1}^{n} f_{i}^{3} S_{i} \exp \left(\frac{8 \pi^{2} f_{i}^{2} z}{g}\right) \hat{\boldsymbol{e}}_{i}^{W} \Delta f_{i}$,

where $f_{i}$ is the band center frequency, $\Delta f_{i}$ the bandwidth, $\hat{\boldsymbol{e}}_{i}^{W}$ a unit vector in the band mean direction, and $g$ the gravity acceleration. The grid-cell-averaged value is computed following Appendix B of Harcourt and D'Asaro (2008). For simplicity, we are ignoring the effect of wave spreading, which may result in an overestimation of the Stokes drift (e.g., Webb and Fox-Kemper, 2015). Note that unlike $\mathrm{Li}$ et al. (2019), we are not including the contribution of a $f^{-5}$ spectral tail beyond the cutoff frequency. A spectral tail contributes more to the surface value of Stokes drift, but much less to the surface layer (here upper $20 \%$ of the mixed layer) averaged Stokes drift, which is used in the Langmuir turbulence parameterizations here. Stokes drift estimated from Eq. (4) may not always be aligned with the wind. Wind-wave misalignment significantly affects the intensity of Langmuir turbulence and thereby the turbulent mixing (see, e.g., Van Roekel et al., 2012). Some of such effects are parameterized in KPPLT-VR12 and KPPLT-LF17 (see Li et al., 2016). But a detailed exploration of such effects at OSPapa may require large eddy simulations under the same realistic forcing conditions, which is beyond the scope of this study.

The annually averaged net heat flux and freshwater flux over this 1-year period are $31.7 \mathrm{~W} \mathrm{~m}^{-2}$ and $12.9 \mathrm{mg} \mathrm{m}^{-2} \mathrm{~s}^{-1}$, respectively. Such imbalance of the heat and freshwater fluxes would increase the temperature of a water column of 

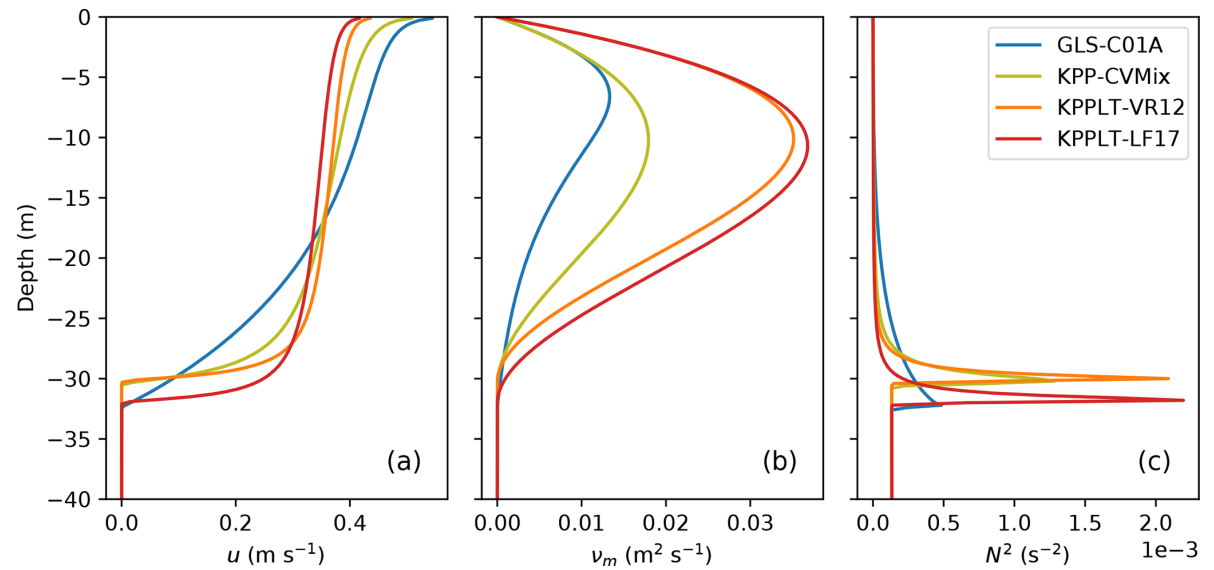

Figure 2. Vertical profiles of (a) down-wind velocity $u$, (b) turbulent viscosity $v_{m}$, and (c) squared buoyancy frequency $N^{2}$ at the end of the $30 \mathrm{~h}$ simulations.

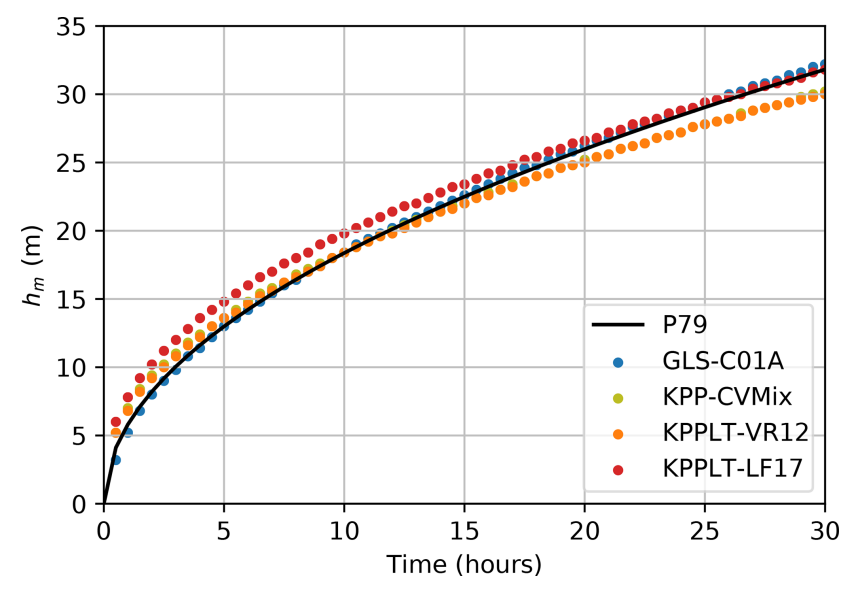

Figure 3. A comparison of the time evolution of the mixed layer depth $h_{\mathrm{m}}$ in GOTM simulations defined by the depth at which $N^{2}$ reaches its maximum in color, and the prediction of Price (1979) in Eq. (2) in black.

$100 \mathrm{~m}$ by about $2.5^{\circ} \mathrm{C}$ over a year, and decrease the salinity by about $0.1 \mathrm{~g} \mathrm{~kg}^{-1} .{ }^{1}$ To directly compare with the temperature and salinity measurements in single-column simulations over a long period, such imbalance in the heat and freshwater fluxes needs to be compensated by careful adjustments to account for the effects of vertical advection and lateral processes (e.g., Large, 1996). Our focus here is to show the effects of parameterizing Langmuir turbulence in GOTM. Therefore, instead of trying to balance the heat and freshwater budget in a rather empirical way, we break the seasonal cycle into four relatively shorter stages (see Fig. 4). These four stages roughly represent (I) the spring restratification, (II) stable forcing in summer, (III) mixed layer entrainment

\footnotetext{
${ }^{1}$ In this estimate, we assume the seawater has a density of $1026 \mathrm{~kg} \mathrm{~m}^{-3}$, a specific heat of $3985 \mathrm{~J} \mathrm{~kg}^{-1}{ }^{\circ} \mathrm{C}^{-1}$ and a salinity of $33 \mathrm{~g} \mathrm{~kg}^{-1}$.
}

in fall and winter, and (IV) preconditioning for restratification in winter, each of the stages being initialized by observed temperature and salinity profiles. In this way, the differences between different vertical mixing schemes can be shown under different forcing regimes, using the observation as a reference, and the accumulative effects of the ignored vertical advection and lateral processes are reduced.

As shown in Fig. 4e, all four vertical mixing schemes predict warmer SST than the observation throughout the year, especially in stages II and III, and saltier SSS in stage III and slightly fresher SST in stage IV. This is likely a result of missing the vertical advection and lateral processes. Correspondingly, the MLD in all four vertical mixing schemes except KPPLT-LF17 is mostly shallower than the observation throughout the year, especially in stage III and during sporadic mixed layer deepening events in stages I and IV (Fig. 4g). As expected, incrementally including the effects of Langmuir-turbulence-enhanced mixing and entrainment in KPPLT-VR12 and KPPLT-LF17 makes the MLD deeper and SST cooler. KPPLT-LF17 appears to match the observation the best. We note that this is not sufficient evidence of KPPLT-LF17 outperforming KPPLT-VR12 and KPP-CVMix without carefully accounting for the effects of vertical advection and lateral processes. However, this result suggests that the effects of Langmuir turbulence on SST and MLD are significant and can be comparable to the effects of vertical advection and lateral processes at OSPapa.

Figure 5 shows the temperature and salinity profiles at the end of each stage at OSPapa. All four vertical mixing schemes give too-sharp temperature and salinity gradients at the base of the mixed layer than the observation, and, especially in stages I and II, too-strong temperature gradient within the mixed layer. Again, we can see that KPPLT-LF17 appears to match the observed profiles the best, while KPPCVMix performs the worst. The differences in the shape of the observed and simulated profiles, especially the mismatch below the mixed layer, suggest the importance of other pro- 

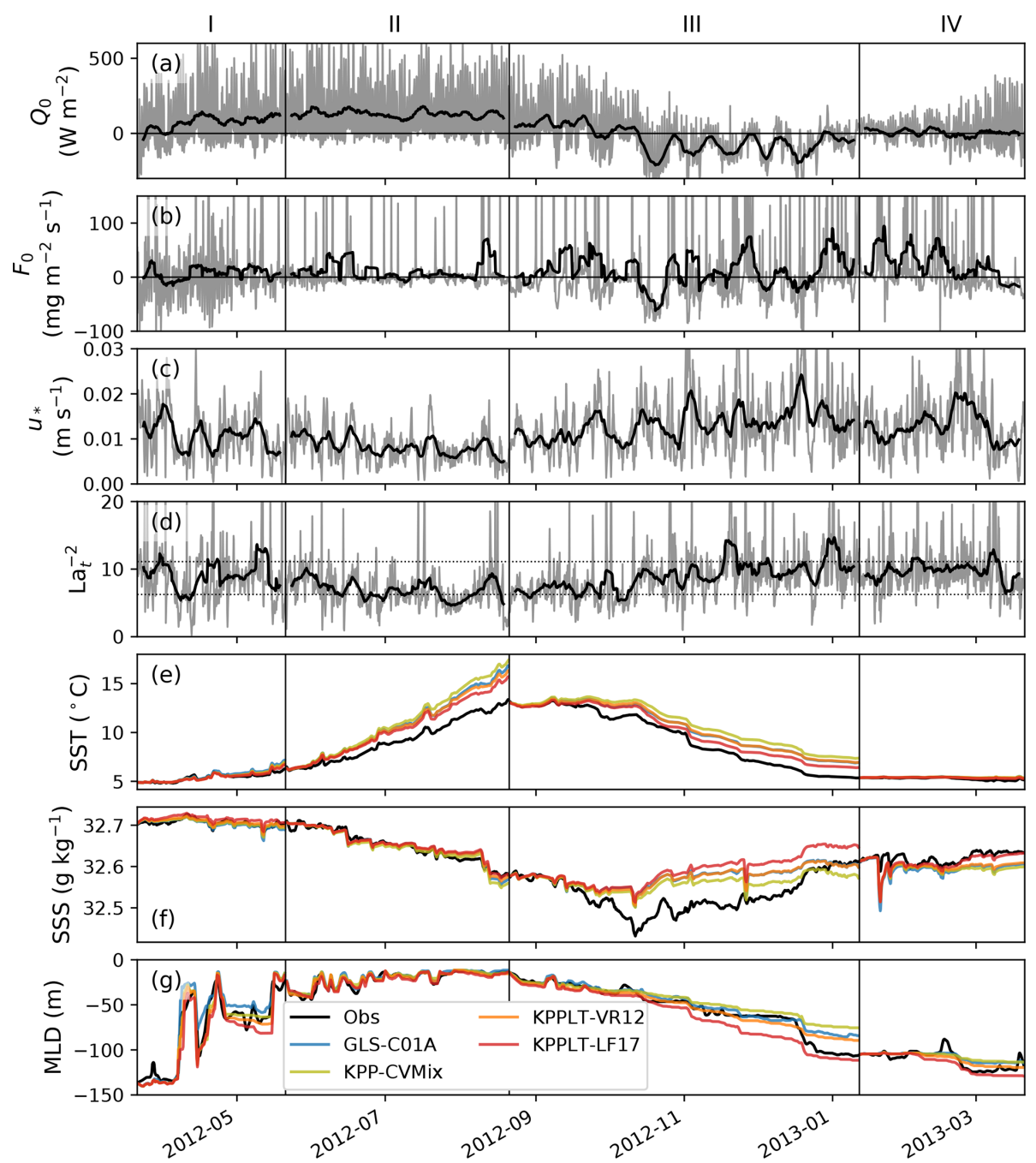

Figure 4. Time series of (a) net surface heat flux $\left(\mathrm{W} \mathrm{m}^{-2}\right.$ ), (b) net freshwater flux (precipitation minus evaporation; $\mathrm{mg} \mathrm{m}^{-2} \mathrm{~s}^{-1}$ ), (c) surface friction velocity $\left(\mathrm{m} \mathrm{s}^{-1}\right)$, (d) $L a_{\mathrm{t}}^{-2}$ where $L a_{\mathrm{t}}$ is the turbulent Langmuir number, (e) sea surface temperature (SST; ${ }^{\circ} \mathrm{C}$ ), (f) sea surface salinity (SSS; $\mathrm{g} \mathrm{kg}^{-1}$ ), and (g) MLD (m) defined by a temperature threshold method following de Boyer Montégut et al. (2004) at Ocean Station Papa. In panels (a)-(d), the thin line in gray shows the 3-hourly time series and the thick line in black shows the $5 \mathrm{~d}$ moving average. The dotted black lines in panel (d) mark the values corresponding to $L a_{\mathrm{t}}=0.3$ and $L a_{\mathrm{t}}=0.4$. In panels (e)-(g), the black line shows the daily averaged measurements at Ocean Station Papa. Daily averaged simulation results of GLS-C01A, KPP-CVMix, KPPLT-VR12, and KPPLT-LF17 are shown in blue, yellow, orange, and red, respectively. In each panel, the 1-year time series is composed of time series of four stages, chosen to roughly represent the conditions of (I) spring restratification, (II) stable forcing, (III) mixed layer entrainment, and (IV) preconditioning for restratification, respectively.

cesses than vertical mixing that are not included in the singlecolumn GOTM simulations here. It is interesting to note that KPP based parameterizations all give sharper density interface at the OSBL base than GLS-C01A. Again, this may be due to the downward diffusion of TKE into the interface in GLS-C01A, which is missing in KPP.

Figure 6 highlights the effects of parameterizing Langmuir turbulence by comparing the simulated temperature evolution in GOTM between the four parameterizations. Consistent with Li et al. (2019), the effects of Langmuir turbulence in KPPLT-VR12 and KPPLT-LF17 are strongest during mixed layer deepening in the fall (stage III) and the sporadic mixing events when the mixed layer is shallow (stage II). Its effects are weaker when the mixed layer is deep in winter (stages I and IV), even though both the winds and waves are stronger in winter (Fig. 4c, d). Such effects of Langmuir turbulence in KPP-based parameterizations are significant as compared to the difference between KPP-CVMix and GLSC01A.

To test the sensitivity of the Langmuir turbulence parameterizations to the uncertainties in estimating the Stokes drift, we repeat the GOTM simulations with Stokes drift estimated 

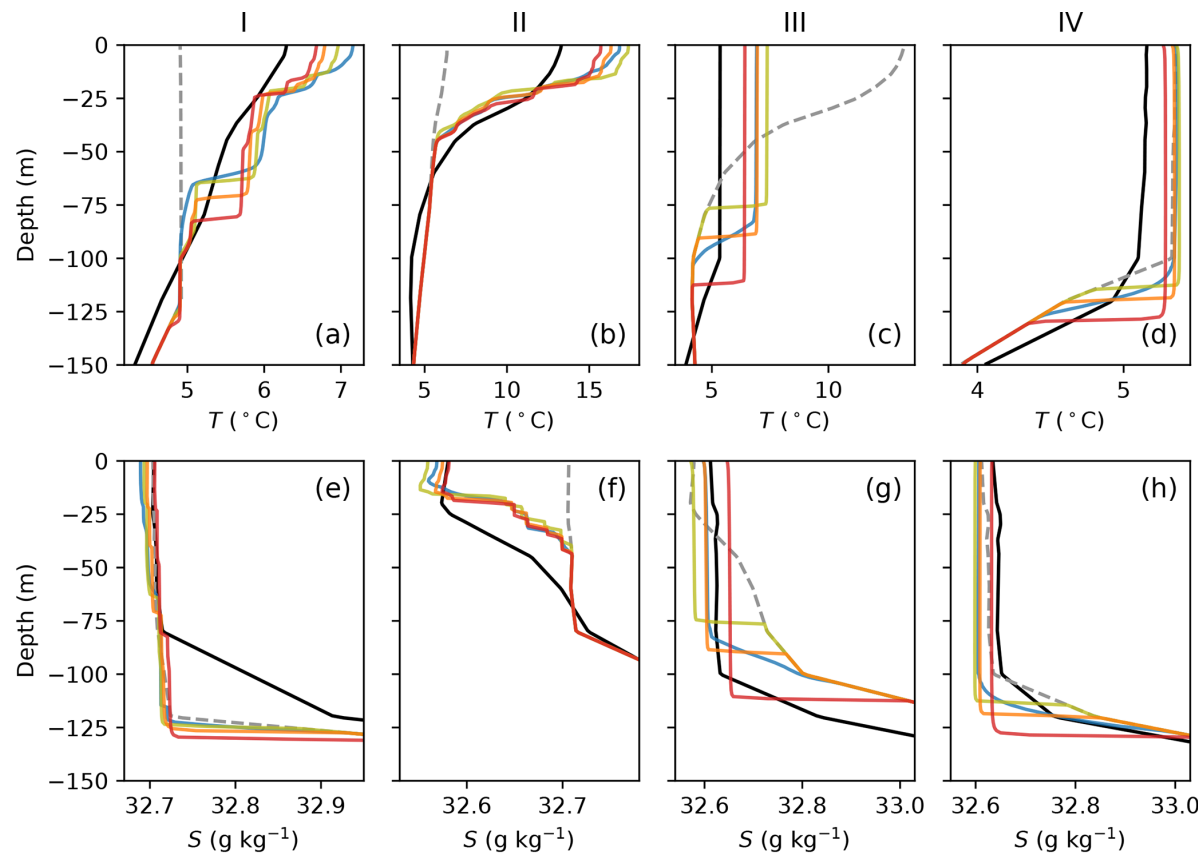

- Obs - GLS-C01A KPP-CVMix

- KPPLT-VR12

KPPLT-LF17

Figure 5. A comparison of the vertical profiles of the daily mean temperature (a-d) and salinity (e-h) at Ocean Station Papa between the observation (black) and GOTM simulations (colored). The four columns show the profiles at the end of the four stages shown in Fig. 4. The dashed line in gray in each panel shows the initial condition at the beginning of each stage.

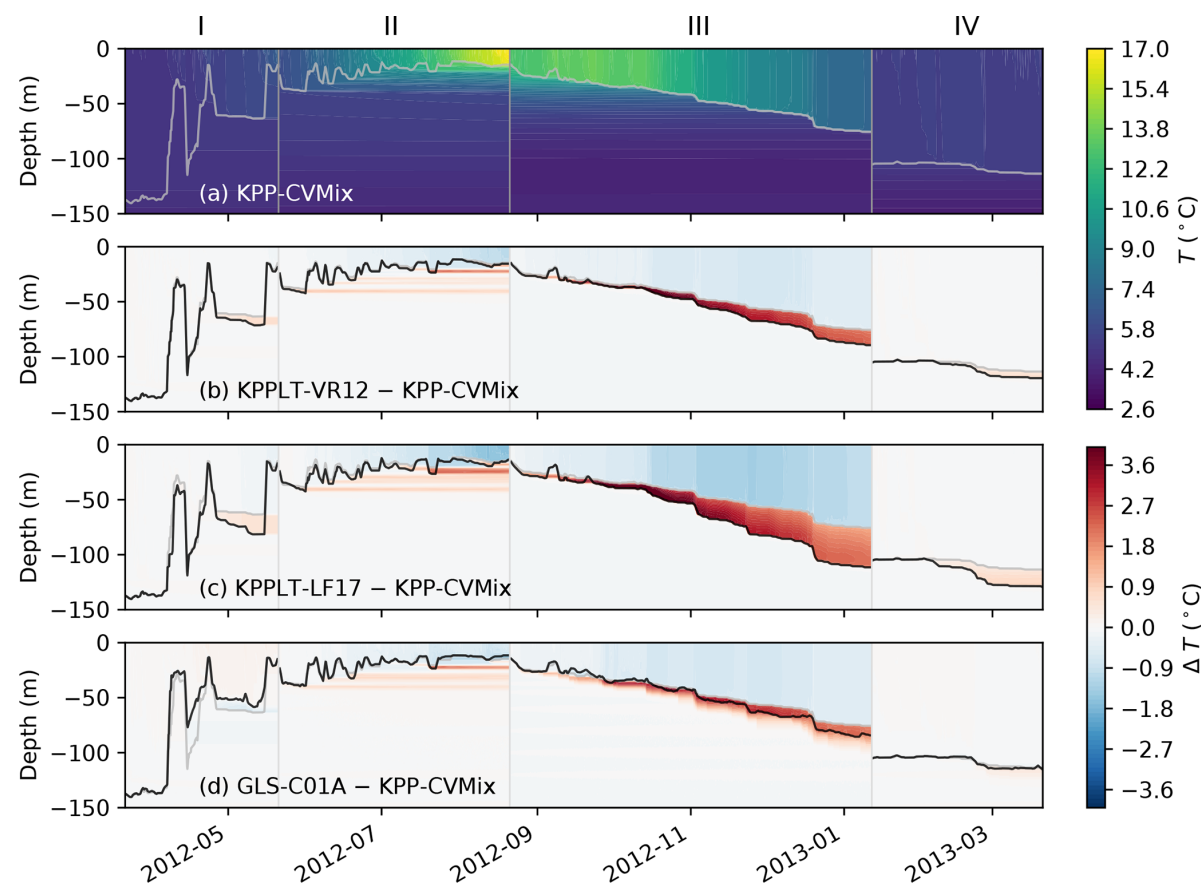

Figure 6. Hovmöller diagrams comparing the simulated temperature between the four vertical mixing schemes at Ocean Station Papa. Panel (a) shows the simulated temperature in KPP-CVMix. Panels (b)-(d) show the differences from KPP-CVMix in KPPLT-VR12, KPPLTLF17, and GLS-C01A, with the black line showing the MLD. In all panels, the gray line shows the MLD in KPP-CVMix as a reference. KPP-CVMix is used as the reference here simply for better visualization of the effects of Langmuir turbulence parameterizations (b, $\mathbf{c}$ ). 
from (i) the "theory wave" approach in Li et al. (2017) and (ii) an idealized exponential profile assuming $\delta^{\mathrm{S}}=5 \mathrm{~m}$ and $L a_{\mathrm{t}}=0.3$ in Eqs. (1) and (3). The "theory wave" estimate of Stokes drift is often an underestimate as the effects of swell are largely ignored. The exponential profile, which represents an idealized swell (but in the direction of the local wind), is likely an overestimation of the Stokes drift for most cases, especially given that the Stokes drift in the real ocean typically decay much faster than exponential (Webb and FoxKemper, 2011, 2015). This is indeed the case for OSPapa, as shown in Fig. 7 which compares the distributions of the Stokes drift profiles estimated from the "theory wave" approach (blue) and an exponential profile (green) with that computed from the observed wave spectrum (black). Here, the Stokes drift profiles are normalized by the surface friction velocity as Stokes drift tends to vary with the wind (see Fig. 4c, d). Note that there is a seasonal variation of the relation between Stokes drift and the wind at OSPapa that is better captured by the "theory wave" estimate but not in the exponential profile estimate (stage II).

Figure 8a, b compare the time series of $L a_{\mathrm{t}}^{-2}$ and $L a_{\mathrm{SL}}^{-2}$ from the two estimates of Stokes drift with that computed from the observed wave spectrum, where $L a_{\mathrm{SL}}$ is the surfacelayer-averaged Langmuir number (Harcourt and D'Asaro, 2008),

$L a_{\mathrm{SL}}=\left(\frac{u_{*}}{\left\langle u^{\mathrm{S}}\right\rangle_{\mathrm{SL}}-u_{\mathrm{ref}}^{\mathrm{S}}}\right)^{1 / 2}$,

in which $\left\langle u^{\mathrm{S}}\right\rangle_{\mathrm{SL}}$ is the surface-layer-averaged Stokes drift and $u_{\text {ref }}^{\mathrm{S}}$ is a reference Stokes drift at the base of the mixed layer. The "theory wave" approach of Li et al. (2017) gives a slightly smaller estimate of the Stokes drift and the exponential profile approach gives a much bigger estimate for most of the times, especially for the surface-layer-averaged values. Panels (c)-(e) compare the simulated SST, SSS and MLD between the three simulations. It is seen that KPPLTVR12 and KPPLT-LF17 give very similar results with both of the two estimates of Stokes drift and that computed from the observed wave spectrum, except the SST in stage II where the exponential profile approach significantly overestimates the Stokes drift and therefore Langmuir-enhanced mixing and near-surface cooling. This is consistent with the findings of Li et al. (2017), suggesting that we may use the "theory wave" estimate of Stokes drift for KPPLT-VR12 and KPPLTLF17 in GOTM simulations for cases where sufficient wave measurements are not available, such as for the two cases discussed in the following sections. It should be noted that both KPPLT-VR12 and KPPLT-LF17 use only the Langmuir numbers to parameterize the effects of Langmuir turbulence, which are relatively insensitive to the exact profile of Stokes drift. For vertical mixing schemes that depend on the full profile of Stokes drift (e.g., Harcourt, 2013, 2015), this "theory wave" estimate might not be sufficient.

\subsection{FLEX}

The Fladen Ground Experiment (FLEX) test case is based on an intensive field campaign carried out in spring 1976 in the northern North Sea at $58^{\circ} 55^{\prime} \mathrm{N}$ and $0^{\circ} 32^{\prime} \mathrm{E}$ at a depth of about $145 \mathrm{~m}$. Between 6 April and 13 June, regular CTD (conductivity-temperature-depth) profiles were sampled that were compiled by Soetje and Huber (1980) into vertical profiles of potential temperature and salinity. These profiles show the transition from fully mixed to stratified conditions in the upper half of the water column with a top-to-mid-depth temperature difference of $4 \mathrm{~K}$. The salinity stratification remains weak with a maximum bottom to top difference of $0.1 \mathrm{~g} \mathrm{~kg}^{-1}$. Bottom-generated turbulence due to weak tidal currents keeps the lower half of the water column mixed and supports deepening of the thermocline. The meteorological forcing was highly variable including several storms that led to intermittent mixed layer deepening. Ship-based meteorological data for wind speed, dry and wet air temperature, air pressure, shortwave radiation, and longwave back radiation are available. Since lateral advection is weak in this region and the development of thermal stratification depends on a subtle balance of stratifying forces of surface warming and de-stratifying forces of wind and tidal mixing, the FLEX data set has become a standard test case for surface mixed layer models (e.g., Friedrich, 1983; Frey, 1991; Burchard and Baumert, 1995; Burchard et al., 2006) including GOTM.

Since the focus of the present model development is on the surface boundary layer and CVMix does not contain a bottom boundary layer module at the moment, we simulate the FLEX test case with our four vertical mixing schemes without tidal forcing. However, to illustrate the relative effect of Langmuir turbulence versus tidal forcing, we also run GLSC01A with tidal forcing as a reference.

Here, all five GOTM simulations are initialized with temperature and salinity profiles from 6 April 1976, and run through 7 June 1976, forced by hourly meteorological data. The surface heat flux is computed internally in GOTM from the meteorological data following Fairall et al. (1996). The surface freshwater flux is ignored. The local depth is $145 \mathrm{~m}$, resolved with 145 evenly distributed grid cells. A time step of $360 \mathrm{~s}$ is used, and 3-hourly output is analyzed here. Since stratification is dominated by temperature in this case, the salinity field is relaxed towards the observations on a timescale of $48 \mathrm{~h}$, and we focus our discussion on the temperature field.

There are no direct measurements of ocean surface waves in the FLEX case; therefore, we are using the "theory wave" approximation of Li et al. (2017) to estimate the Stokes drift from the wind speed, assuming that wind and waves are aligned. As demonstrated in the previous section, this approximation provides a reasonable estimate of the Stokes drift in our Langmuir turbulence parameterizations KPPLTVR12 and KPPLT-LF17. 

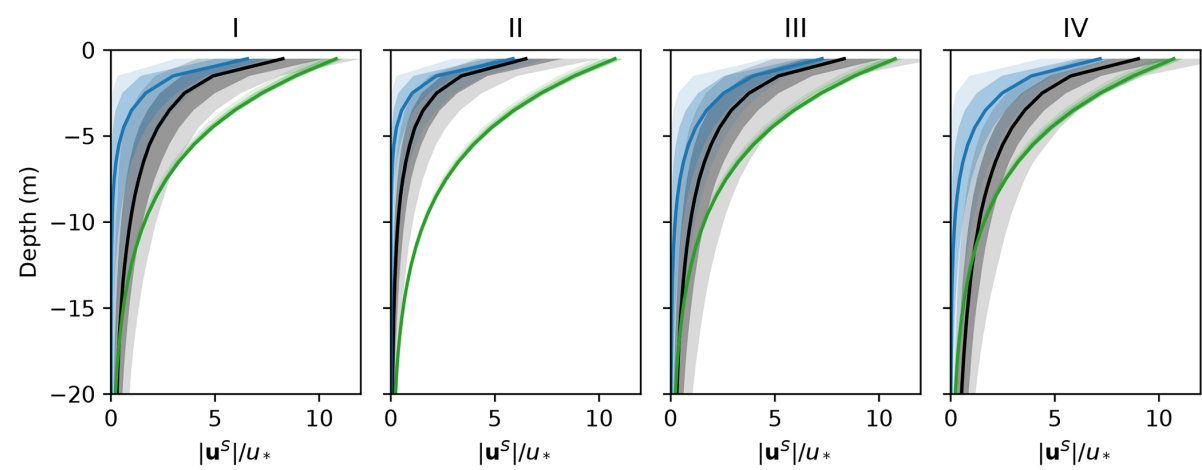

Spectrum — Li et al. (2017) — Exponential

Figure 7. A comparison of the Stokes drift profiles estimated from the observed wave spectrum in black, "theory wave" approach of Li et al. (2017) in blue and an idealized exponential profile with $L a_{\mathrm{t}}=0.3$ and $\delta^{S}=5 \mathrm{~m}$ in green during the four stages of a seasonal cycle at Ocean Station Papa. Stokes drift is normalized by the surface friction velocity $u_{*}$. The lines show the median, and the dark and light shadings enclose $50 \%$ (25th to 75 th percentiles) and $80 \%$ (10th to 90th percentiles) occurrence during each stage.

Consistent with previous studies, GLS-C01A reproduces the observed SST and MLD with good accuracy (blue versus black lines in Fig. 9d, e). The tidal forcing has very small impact on the simulated SST and MLD (dashed versus solid lines in blue), providing some support for neglecting the tides in following discussion of the KPP simulations (see above). The SSTs predicted by the three variants of KPP are generally close to that computed by GLS-C01A, with progressively cooler SST the more effects of Langmuir turbulence are accounted for. Accordingly, the MLD is the deepest in KPPLT-LF17 and shallowest in KPP-CVMix. Similar to stage I of the OSPapa case (see Fig. 4g), the effect of Langmuir-induced entrainment in KPPLT-LF17 is most effective in the sporadic mixed layer deepening events, especially around 12 May (Julian day 133) when a storm passed across the site (e.g., Burchard and Baumert, 1995).

Figure 10 compares the simulated temperature distribution with the observations. To highlight the effects of tidal forcing and Langmuir turbulence, panel (c) shows the difference in GLS-C01A with and without tidal forcing, and panels (e) and (f) show the differences in KPP with and without Langmuir turbulence. Both GLS-C01A and KPP-CVMix appear to reproduce the dominant features in the evolution of the temperature profile. Specifically, stratification gradually develops, with sporadic mixing events until around 12 May when a storm passed and mixed the water in the upper $50 \mathrm{~m}$. Afterwards, a second surface warm layer of about $20 \mathrm{~m}$ develops on top of the deeper mixed layer. KPP-CVMix gives slightly shallower initial restratification than GLS-C01A from around 22 April to 6 May (see the solid white lines in panels $b$ and d). The effects of Langmuir turbulence in deepening the mixed layer are apparent during this time (see panels e and d) but more significant when the storm passed around 12 May, resulting in cooler temperature within the mixed layer and warmer at the base of the mixed layer as compared to KPPCVMix. Such effects are comparable in magnitude to the ef- fect of tidal forcing. As shown in panel (c), the inclusion of tides increases the mixing across the thermocline, and thus across the entire water column, which is reflected in a cooling of the mixed layer and a warming of the underlying layers. The tidal mixing across the thermocline will likely redistribute the Langmuir-induced warming at the mixed layer base down to deeper layers, resulting in even stronger cooling of the mixed layer and warming underneath.

Since the current implementation of KPP in CVMix does not contain a bottom boundary layer module, we are not able to assess the combined effects of Langmuir turbulence and tides with these KPP variants. Even if we had included a bottom boundary layer module in KPP, special treatment would have been needed when the surface and bottom boundary layers start impinging on each other (e.g., Durski et al., 2004). A second-moment closure scheme that includes the effects of Langmuir turbulence (e.g., Harcourt, 2013, 2015) will likely be more helpful to directly quantify the combined effects of Langmuir turbulence and tides.

\subsection{Gotland Basin}

Finally, we tested the four vertical turbulent mixing schemes in the central eastern Gotland Basin of the Baltic Sea $\left(57.3^{\circ} \mathrm{N}, 20.0^{\circ} \mathrm{E}\right)$. The primary goal of this analysis is to test the performance of these schemes in a multi-year simulation of a non-tidal basin that remains stratified throughout the year due to a permanent halocline (Feistel et al., 2008). A detailed description of the GOTM setup for the Gotland Basin is described in Burchard et al. (2006).

Here, we used the hourly meteorological forcing from the COSMO-REA6 regional reanalysis data for continental Europe (Bollmeyer et al., 2015). The GOTM simulations were carried out for the years 1997-2002, during which the mean net heat flux from this data set was $-1.1 \mathrm{~W} \mathrm{~m}^{-2}$. A vertical domain of $250 \mathrm{~m}$ (corresponding to the deepest 

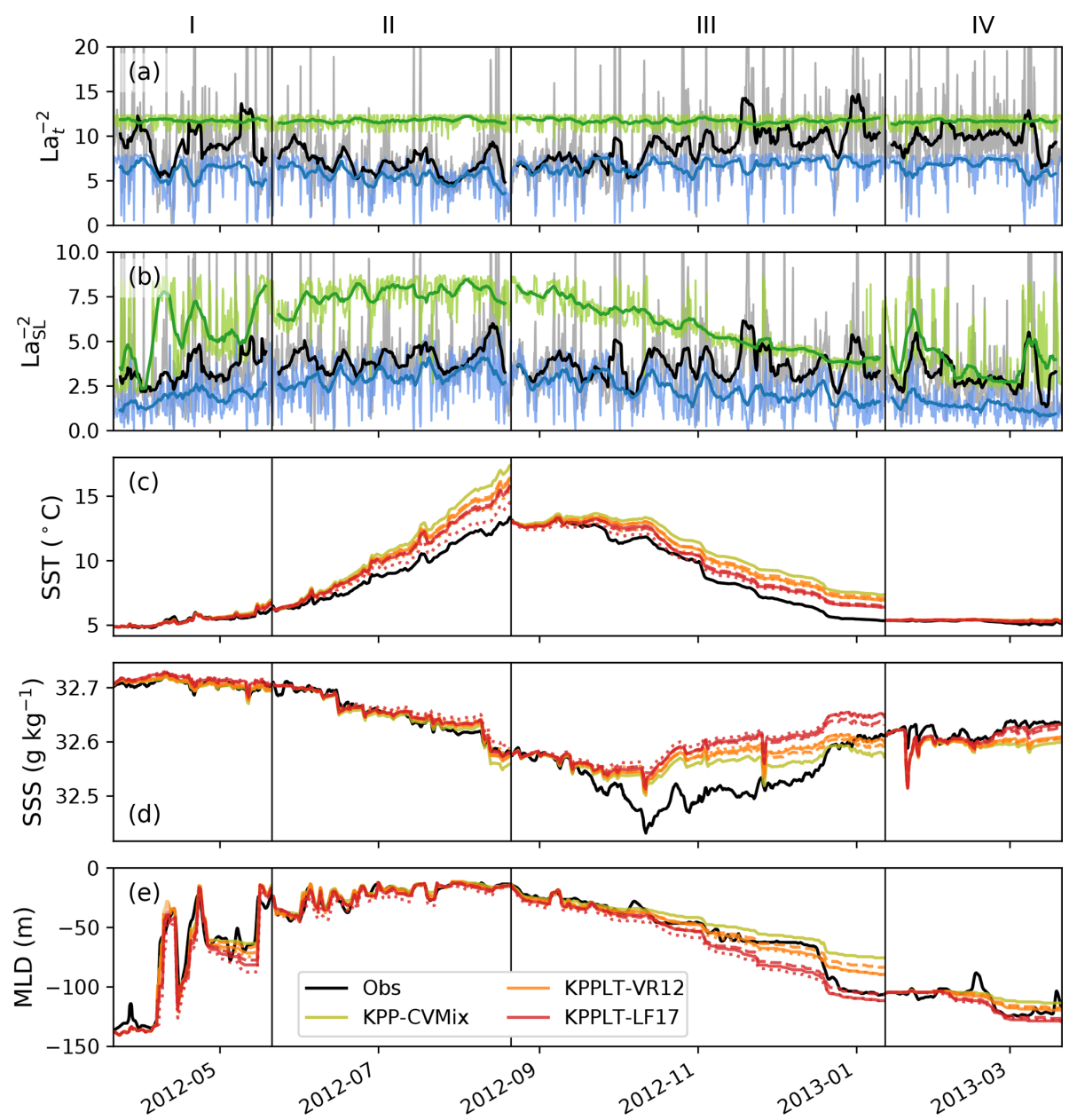

Figure 8. Time series of (a) $L a_{\mathrm{t}}^{-2}$, where $L a_{\mathrm{t}}$ is the turbulent Langmuir number, (b) $L a_{\mathrm{SL}}^{-2}$, where $L a_{\mathrm{SL}}$ is the surface-layer-averaged Langmuir number, (c) sea surface temperature (SST; $\left.{ }^{\circ} \mathrm{C}\right)$, (d) sea surface salinity (SSS; $\mathrm{g} \mathrm{kg}^{-1}$ ), and (e) MLD (m) defined by a temperature threshold method following de Boyer Montégut et al. (2004) at Ocean Station Papa. In panels (a) and (b), the thin line in gray shows the 3-hourly time series and the thick line in black shows the $5 \mathrm{~d}$ moving average estimated from the wave spectrum using Eq. (4). The blue lines show the same for the "theory wave" estimate of Stokes drift following Li et al. (2017) and green lines for the exponentially decaying Stokes drift assuming $L a_{\mathrm{t}} \approx 0.3$ and $\delta^{\mathrm{S}}=5 \mathrm{~m}$. Solid lines in panels (c)-(e) show the same results as in panels (e)-(g) of Fig. 4. Dashed lines show the results with Stokes drift estimated from the "theory wave" approach. Dotted lines show the results with the idealized exponential Stokes drift.

point of the basin) was discretized with 250 evenly spaced vertical layers and a time step of $10 \mathrm{~min}$. Daily output was saved for the analysis. Salinity was nudged to observations, available at approximately 3-month resolution from a governmental monitoring program, with a relaxation timescale of $50 \mathrm{~d}$. Similar to the FLEX test case, we are focusing our discussion on the temperature field. The EU Copernicus Marine Environment Monitoring Service (CMEMS) wave hindcast simulation of the Baltic Sea (https://resources. marine.copernicus.eu/?option $=$ com_csw $\&$ view $=$ details $\&$ product_id=BALTICSEA_REANALYSIS_WAV_003_015, last access: 1 July 2021), forced by the ECMWF's ERA5 reanalysis products, was used to provide the hourly data for the wave variables in the Gotland Basin. The simulated significant wave height in the Baltic Sea wave model product is validated against the observations at the northern Baltic wave buoy (https://www.emodnet-physics.eu/map/platinfo/ PIROOSDownload.aspx?PlatformID $=8793$, last access: 1 July 2021) in the northern part of the central Baltic Sea (not shown).

Since for this wave product, only the surface Stokes drift was available, we estimated the Stokes drift profiles from an approach similar to the "theory wave" estimate of $\mathrm{Li}$ et al. (2017). These authors approximate the vertical profile of the Stokes drift by assuming a wave spectrum proportional to $f^{-5}$ (where $f$ is the frequency) and the directional spreading correction of Webb and Fox-Kemper (2015), subject to constraints on the peak frequency, the surface Stokes drift, 

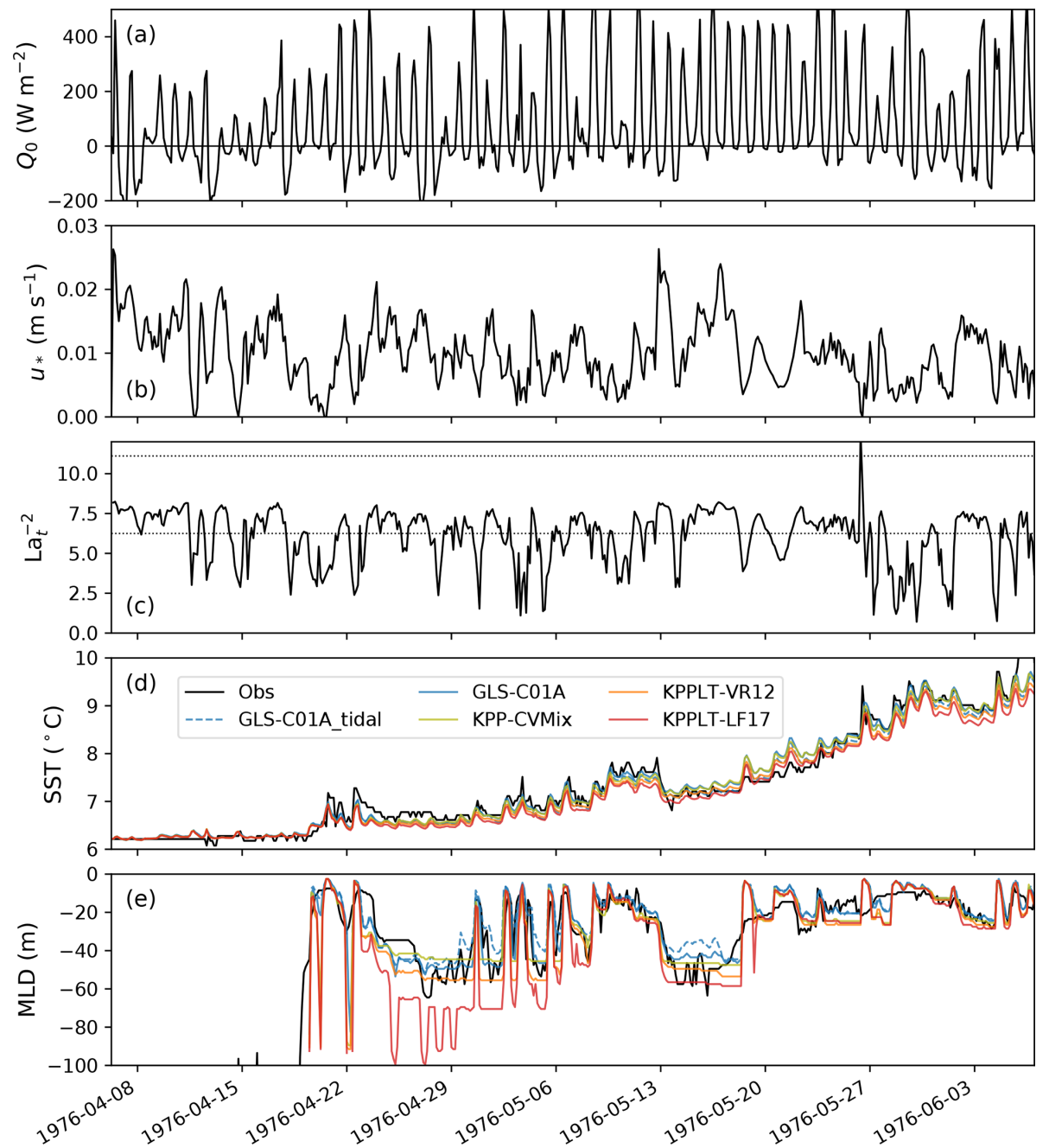

Figure 9. The 3-hourly time series of (a) net surface heat flux $\left(\mathrm{W} \mathrm{m}^{-2}\right)$, (b) surface friction velocity $\left(\mathrm{m} \mathrm{s}^{-1}\right),(\mathbf{c}) L a_{\mathrm{t}}^{-2}$, where $L a_{\mathrm{t}}$ is the turbulent Langmuir number, (d) sea surface temperature (SST; ${ }^{\circ} \mathrm{C}$ ), and (e) $\mathrm{MLD}(\mathrm{m})$ defined by a $0.2^{\circ} \mathrm{C}$ temperature threshold referenced to the surface, in the FLEX case. The black dotted lines in panel (c) marks the values corresponding to $L a_{\mathrm{t}}=0.3$ and $L a_{\mathrm{t}}=0.4$. In panels (d) and (e), the black line shows the observations, and colored lines in blue, yellow, orange, and red show the simulation results of GLS-C01A, KPP-CVMix, KPPLT-VR12, and KPPLT-LF17, respectively. Results of GLS-C01A with tidal forcing are also shown for reference (dashed lines in blue).

and the vertically integrated Stokes drift, all estimated from the wind speed using empirical relations. Here, we assume the same vertical profile shape but replace the empirical constraints by available data from the wave hindcast simulation. Similar approaches to estimate the full Stokes drift profiles from standard wave model output are also discussed in, e.g., Breivik et al. (2016).

Figure 11a-c shows the time series of the forcing conditions; a comparison of the simulated SST and MLD to the observations in the Gotland Basin is provided in Fig. 11d, e. Consistent with previous test cases, KPP-CVMix gives weaker fall-to-winter mixed layer deepening than GLSC01A. Progressively accounting for additional effects related to Langmuir turbulence in KPPLT-VR12 and KPPLT-LF17 increases the MLD by up to around $15 \mathrm{~m}$ in the late win- ter. However, this does not seem to significantly change the simulated SST. The simulated SSTs in the four simulations are hardly distinguishable from each other at this multi-year timescale and are consistent with the available observations.

Vertical profiles of the simulated temperature in these simulations are compared with the observations at selected dates in Fig. 12. The dates (also marked by gray diamonds in Fig. 11) are selected to roughly represent two seasonal cycles. For some of the observations, multiple measurements spanning a period of a few days were recorded (cluster of plus signs in Fig. 11d, e). It is interesting to note that the SST and MLD estimated from the observed temperature profiles can be very different inside these clusters, suggesting variations due to processes with relatively fast timescales. For this reason, we also show examples of these different tem- 

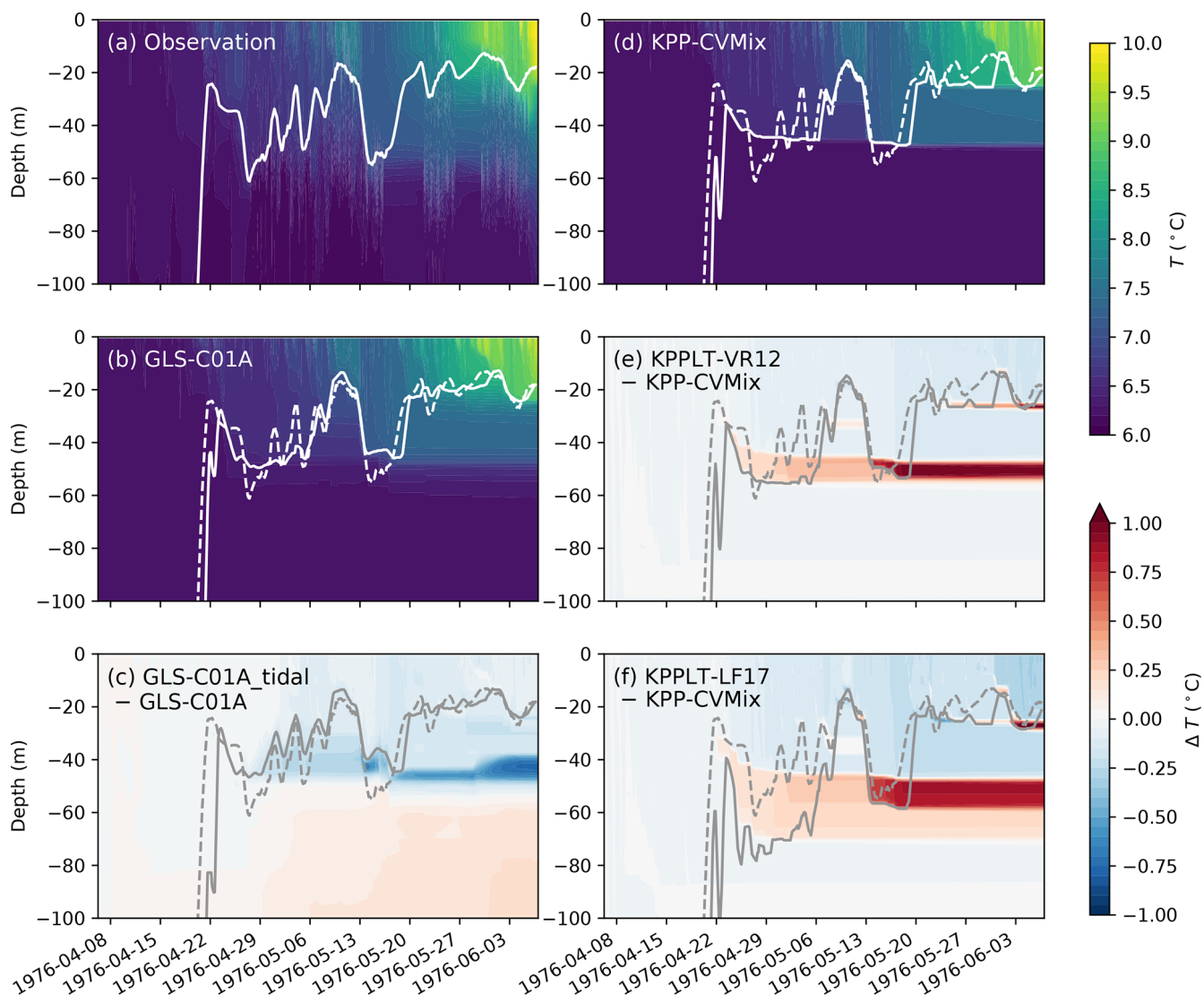

Figure 10. Hovmöller diagrams comparing the observed and simulated temperature between the four vertical mixing schemes in the FLEX case. Panel (a) shows the observed temperature. Panel (b) shows the simulated temperature in GLS-C01A. Panel (c) illustrates the effect of tidal forcing by showing the difference between GLS-C01A with and without tides. Panel (d) shows the simulated temperature in KPPCVMix. Panels (e) and (f) show the differences from KPP-CVMix in KPPLT-VR12 and KPPLT-LF17. Solid lines show the MLD (m) in each case defined by a $0.2^{\circ} \mathrm{C}$ temperature threshold referenced to the surface. For reference, the observed MLD is also shown in panels (b)-(f) in dashed lines.

perature profiles in Fig. 12b, d (dotted lines). The most important observation is that the mixing schemes that include Langmuir effects result in significantly increased MLDs in late fall and early winter, when mixed layer deepening is strongest (Fig. 12d, h). This is consistent with both the weakening of seasonal stratification in the fall and winter, and the design of the mixing schemes that the Langmuirturbulence-induced entrainment is only applied when the surface buoyancy forcing is unstable (the difference between KPPLT-LF17 and KPPLT-VR12; see Li and Fox-Kemper, 2017 for more details). As the thermocline has already been completely eroded during these periods, the mixed layer is bounded from below by the permanent halocline of the Gotland Basin, typically located around 50-70 m depth (not shown). Note that the halocline is maintained in this case by nudging the salinity to observations. This suggest that Langmuir effects significantly contribute to the halocline erosion in winter, which is especially relevant from an ecosystem modeling perspective as the halocline is known to separate the nutrient-depleted surface waters from the nutrient-rich deeper layers (Feistel et al., 2008).

For periods outside the winter months, however, all four vertical mixing schemes give quite similar results, especially during spring (Fig. 12b, f) and summer (Fig. 12c, g). The difference from the observed temperature profiles may be related to processes missing in the single-column model used in our study, for example, those associated with the basinscale doming of the density structure (see, e.g., Fig. 9 in Holtermann et al., 2014).

Figure 13 compares the simulated temperature in the four vertical mixing schemes over the 5-year period. Similar to the OSPapa case (Fig. 6), and the increased MLDs discussed in the context of Fig. 12d, h above, the most apparent differences among the four schemes are found in the phase of fallto-winter mixed layer deepening, with KPPLT-LF17 giving the strongest deepening and KPP-CVMix the weakest. This is expected from both the design of the schemes and from results of previous tests. Overall, the three KPP variants in 

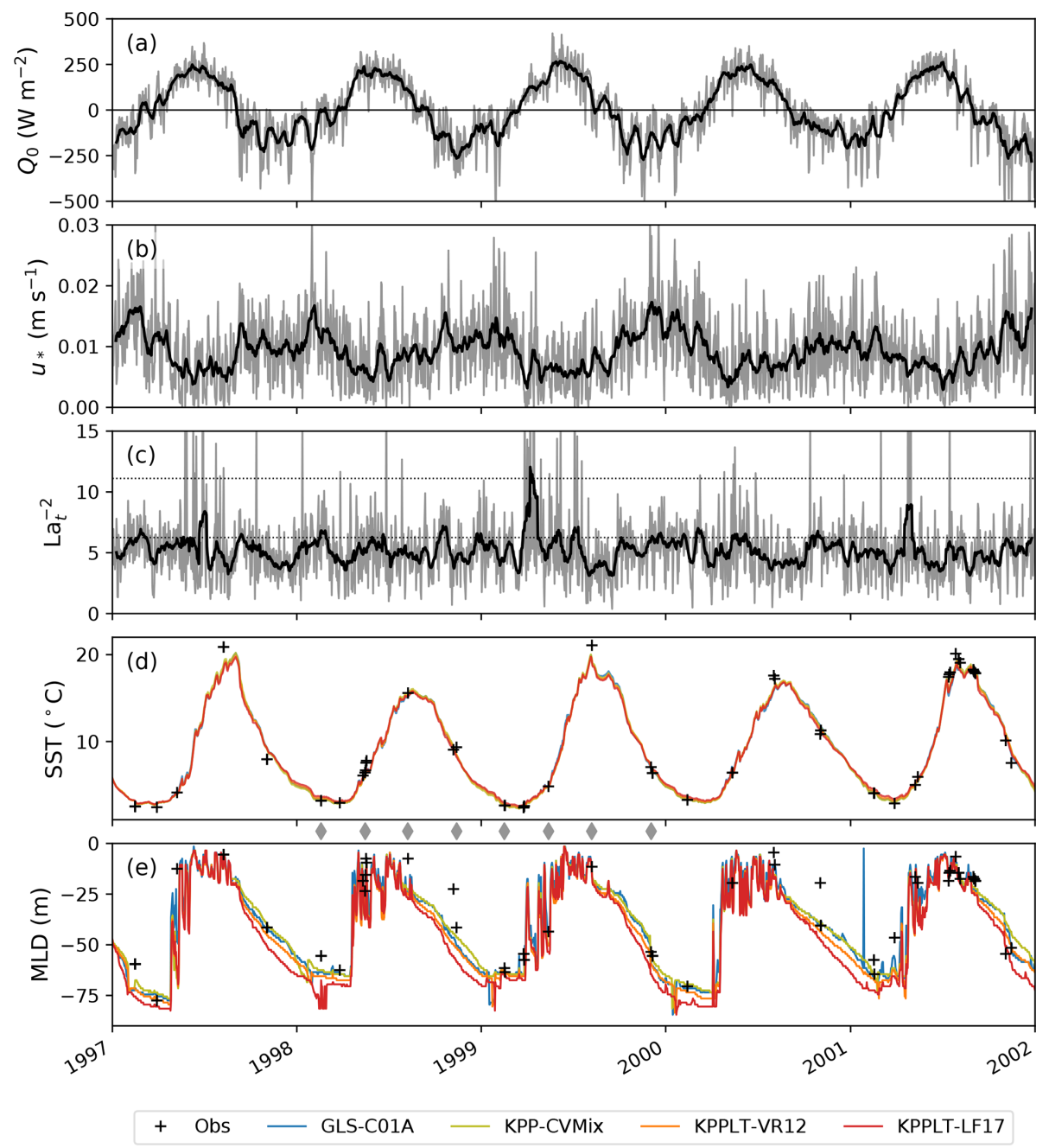

Figure 11. Five-year time series of (a) net surface heat flux $\left(\mathrm{W} \mathrm{m}^{-2}\right)$, (b) surface friction velocity $\left(\mathrm{m} \mathrm{s}^{-1}\right)$, (c) $L a_{\mathrm{t}}^{-2}$ where $L a_{\mathrm{t}}$ is the turbulent Langmuir number, (d) sea surface temperature (SST; ${ }^{\circ} \mathrm{C}$ ), and (e) MLD (m), defined by a $0.2{ }^{\circ} \mathrm{C}$ temperature threshold referenced to the surface, at the Gotland Basin. In panels (a)-(c), the thin line in gray shows the daily time series and the thick line in black shows the $15 \mathrm{~d}$ moving average. The black dotted lines in (c) marks the values corresponding to $L a_{\mathrm{t}}=0.3$ and $L a_{\mathrm{t}}=0.4$. In panels (d) and (e), the black plus signs show the observations at Gotland. Daily results of GLS-C01A, KPP-CVMix, KPPLT-VR12, and KPPLT-LF17 are shown in blue, yellow, orange, and red, respectively. Gray diamonds between panels (d) and (e) mark the time when the vertical profiles of temperature are compared with the observations in Fig. 12.

the newly implemented CVMix module perform reasonably well in this relatively long simulation.

\subsection{Numerical sensitivity and performance}

To illustrate the sensitivity of the four vertical mixing schemes to the vertical resolution and time step, we repeated the OSPapa case with combinations of different vertical resolutions of $\Delta z=[1,5] \mathrm{m}$ and time steps of $\Delta t=$ $[60,600,1800] \mathrm{s}$. These configurations roughly span the range of vertical resolutions and time steps commonly used in regional and global ocean models. Figure 14 shows the simulated temperature and MLD for KPP-CVMix, as well as the deviations from this reference run for coarser vertical resolutions and larger time steps. It is clearly seen that KPPCVMix is very sensitive to the vertical resolution (panels df) but quite insensitive to the time step (panels b, c). This is consistent with what has been shown in previous studies (e.g., Van Roekel et al., 2018; Li et al., 2019). Here, we note that KPP-CVMix is most sensitive to the vertical resolution when the mixed layer is deepening (e.g., throughout phase III and sporadic events in phase II), with stronger deepening when the resolution is coarsened. This is related to the representation of mixed layer entrainment in KPP via a criterion based on the bulk Richardson number, which is particularly sensitive to the detailed choices of the numerics (Van Roekel et al., 2018). Since both KPPLT-VR12 and KPPLT-LF17 are based on KPP-CVMix, they suffer from similar sensitivity to 

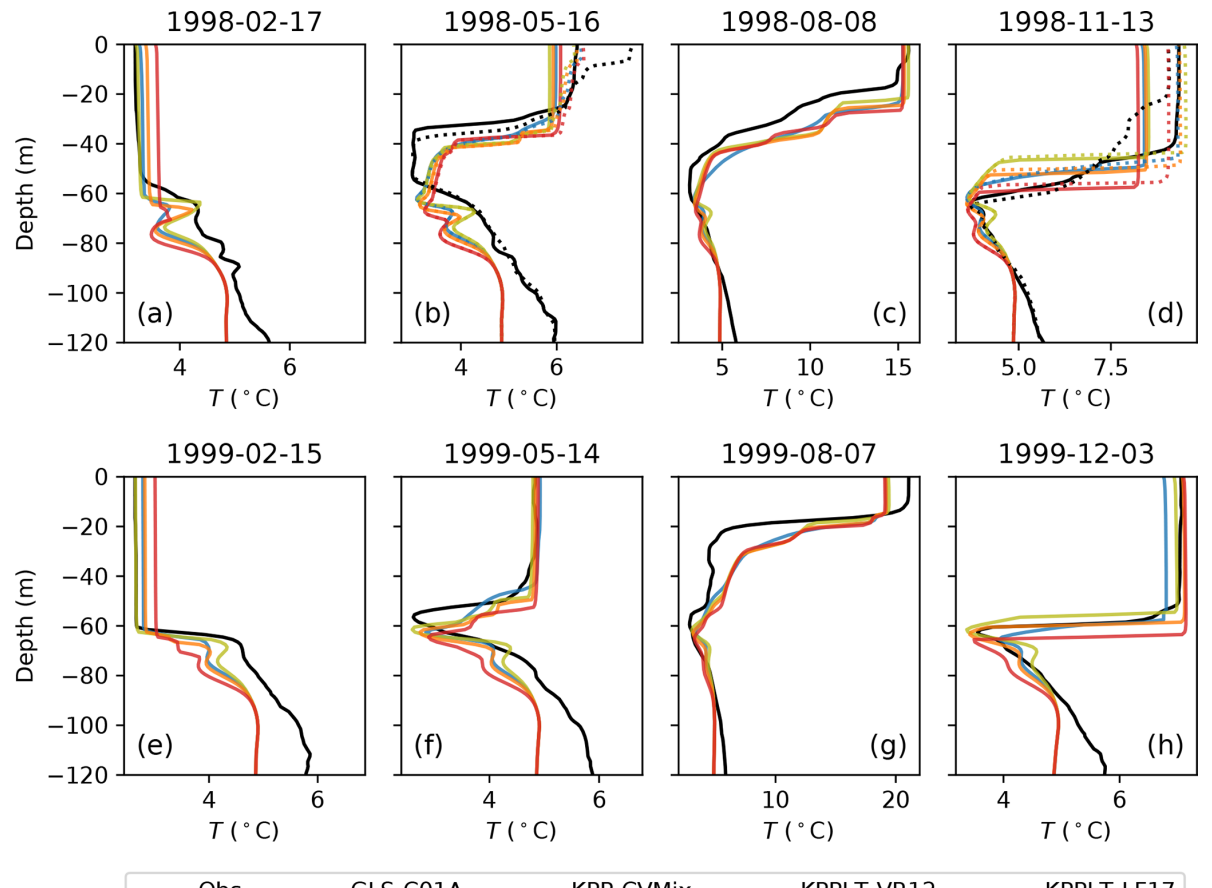

- Obs - GLS-C01A - KPP-CVMix

KPPLT-VR12

KPPLT-LF17

Figure 12. A comparison of the temperature profiles at the Gotland Basin between the observation (black) and GOTM simulations (colored). Profiles at eight time points (marked by gray diamonds in Fig. 11) are shown, representing two typical seasonal cycles. Dotted lines in panels (b) and (d) show another set of profiles 1 or $2 \mathrm{~d}$ apart from the solid lines (see plus signs in Fig. 11d, e), highlighting the faster timescale variations.

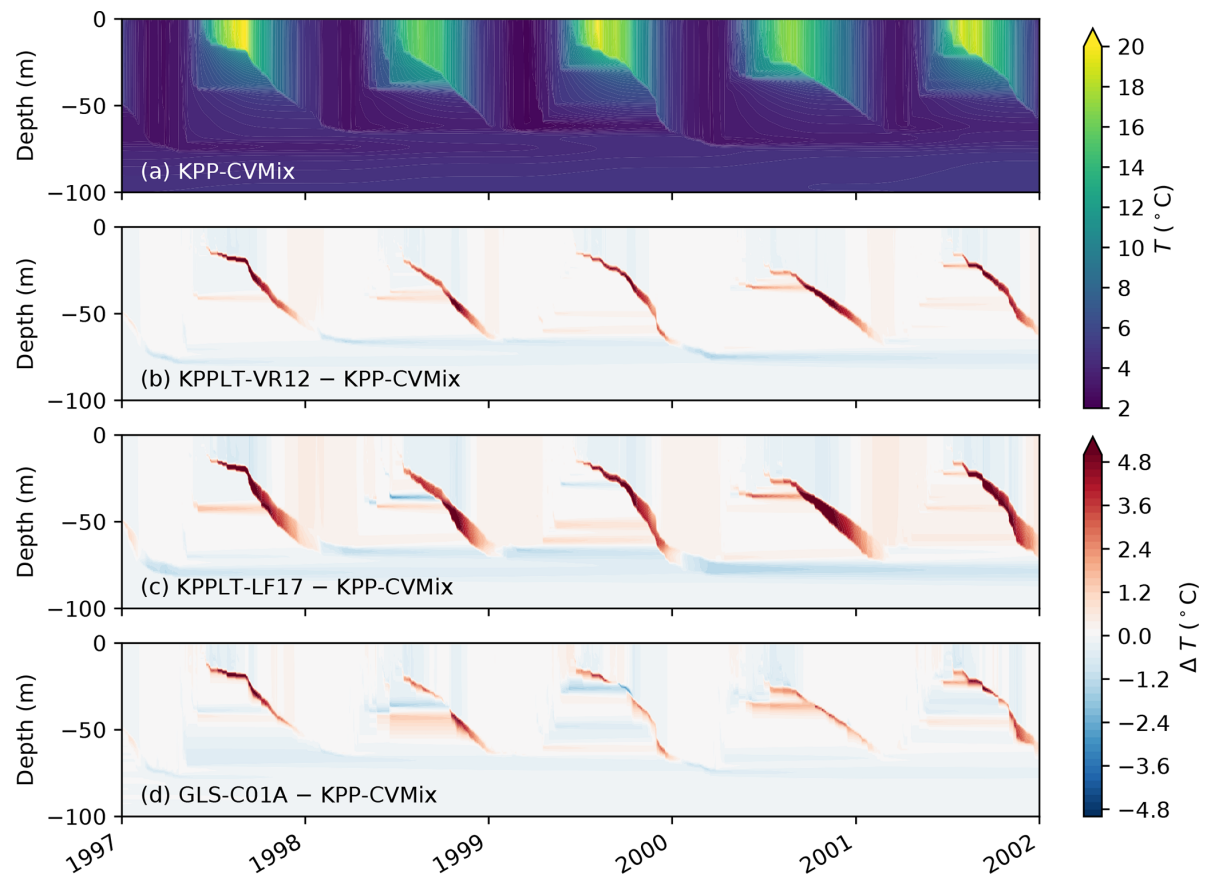

Figure 13. Hovmöller diagrams comparing the simulated temperature between the four vertical mixing schemes at the Gotland Basin. Panel (a) shows the simulated temperature in KPP-CVMix. Panels (b)-(d) show the differences from KPP-CVMix in KPPLT-VR12, KPPLTLF17, and GLS-C01A. 

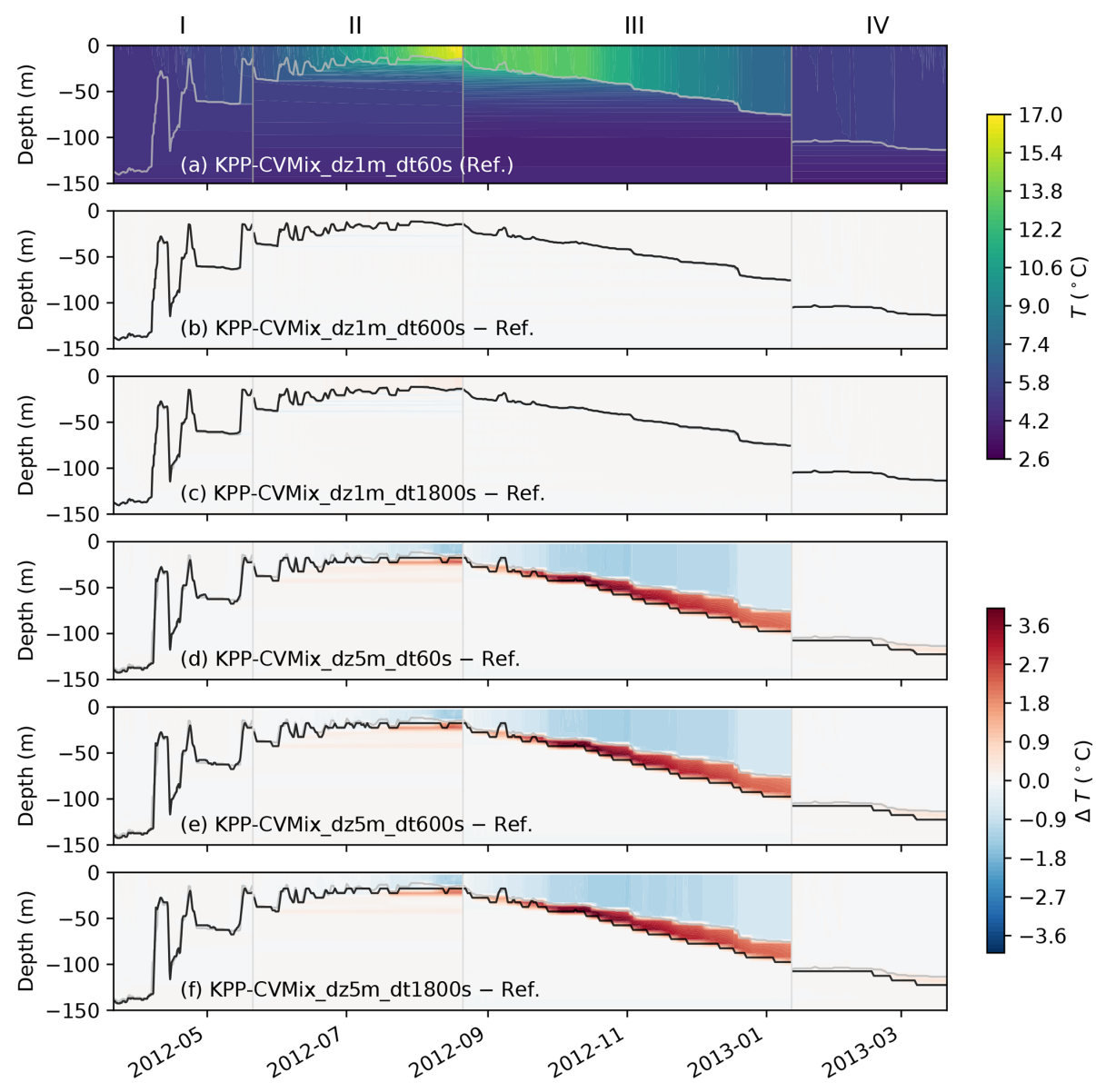

Figure 14. Similar to Fig. 6, but showing the differences in the simulated temperature at Ocean Station Papa in KPP-CVMix with different vertical resolution and time step. Panel (a) shows the simulated temperature in the finest resolution and time step as in Fig. 6 (the reference). Panels (b)-(f) show the differences from the reference with different combinations of coarser vertical resolution and larger time step.

the vertical resolution (not shown). Note, however, that the relative effects of including Langmuir turbulence in KPPLTVR12 and KPPLT-LF17 as shown in Fig. 6 do not change with the vertical resolution.

In comparison, as shown in Fig. 15, GLS-C01A is much less sensitive to the vertical resolution than KPP-CVMix. Fig. $15 \mathrm{~d}$ shows that during the phases of strong mixed layer deepening (in particular, phase III), differences in MLD and mixed layer temperatures are approximately an order of magnitude smaller compared to KPP-CVMix if the grid spacing is increased from 1 to $5 \mathrm{~m}$. However, GLS-C01A is noticeably more sensitive to the time step than KPP-CVMix (Fig. 15b, c). This is likely related to the fact that GLS-C01A solves prognostic equations for the turbulent velocity scale and length scale, as compared to the diagnostic algorithms in KPP. However, the numerical solution of partial differential equations in GLS-C01A has the important advantage that numerical errors are guaranteed to decrease according to the well-defined convergence properties of the numerical schemes if the vertical grid spacing is reduced. For the algorithms in KPP-CVMix, this property cannot be proved.
We also compared the execution (CPU) times in GLSC01A and KPP-CVMix for all the relevant subroutines in each scheme, excluding common subroutines such as the mean flow equations and data input/output. Surprisingly, the CPU time required for a single time step in KPP-CVMix turned out to be 3-4 times larger than for the second-order turbulence model in GLS-C01A. It should be noted that this relative timing information only applies for the specific numerical implementations in GOTM and CVMix used in our study. The actual performance of the corresponding secondorder and KPP mixing schemes may be improved by optimizing the loop structure and the time step, which may also change the relative performance of these models. From a practical point of view, the execution times will also depend on the time step and grid spacing chosen to yield a desired accuracy. As shown above, the second-moment closures in GOTM will tolerate the use of coarser vertical grids, whereas KPP-CVMix will provide sufficient accuracy also for larger time steps. Overall, therefore, our study does not show any clear advantage in computational costs for either model. This is a rather remarkable result as KPP-type models are gener- 


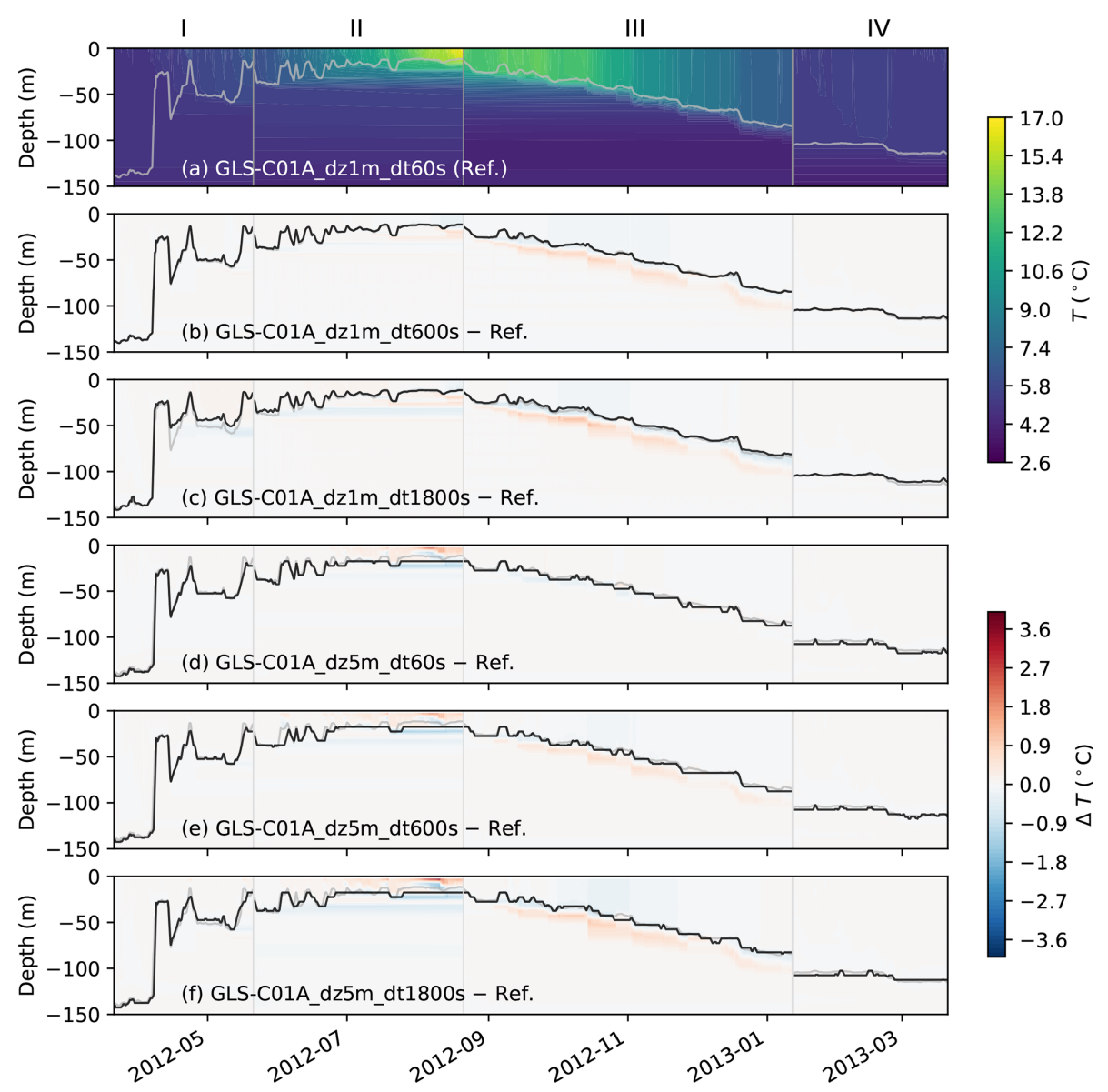

Figure 15. Same as Fig. 14 but for GLS-C01A.

ally believed to be more robust, and therefore preferable, in coarse-resolution global modeling.

\section{Discussions and conclusions}

In this paper, we documented a set of recent extensions of ocean turbulence modeling toolbox GOTM, aiming to incorporate a suite of recently developed vertical mixing schemes that include the effects of Langmuir turbulence. This new capability is realized by adding two modules in GOTM: a CVMix module to interface with the CVMix library and a Stokes drift module to provide the Stokes drift profiles for the Langmuir turbulence parameterizations. These modules were consistently integrated into the existing module structure of GOTM, now also allowing for flexible model setups through the newly developed YAML-based configuration lists, as well as for a straightforward integration of additional Langmuir turbulence parameterizations in the future. For example, future development of CVMix, which has been widely used in many ocean climate models, can now be easily incorporated in GOTM through the new CVMix module, and is therefore available to other ocean models that use
GOTM as their turbulence library with modest code changes. In addition, even though we have demonstrated in Sect. 3.2 that the two variants of KPP with Langmuir turbulence are not particularly sensitive to the details of the Stokes drift profiles (consistent with previous studies), the full Stokes drift profiles are provided by the Stokes drift module, which will facilitate future development and incorporation of Langmuir turbulence parameterizations in the GOTM framework, such as the second-moment closures of Langmuir turbulence by Harcourt $(2013,2015)$.

Using these two new modules in GOTM, three variants of KPP in CVMix, with and without Langmuir turbulence, were tested and compared with a second-moment turbulence closure scheme based on the GLS framework in the $k-\varepsilon$ formulation. We investigated four test cases and evaluated the model performance against available theoretical scalings and observations. These four test cases included an idealized wind-driven entrainment case and three more realistic cases: Ocean Station Papa, the northern North Sea, and the central Baltic Sea, each focusing on slightly different aspects of the vertical mixing processes. The results are consistent with previous studies of Langmuir turbulence effects in KPP (e.g., $\mathrm{Li}$ and Fox-Kemper, 2017; Li et al., 2019). Although the de- 
gree to which we can evaluate these vertical mixing schemes is still limited by the use of single-column simulations, interesting conclusions can still be drawn from the direct comparison with available theoretical scalings and observations, which has never been done particularly for KPPLT-VR 12 and KPPLT-LF17. The effects of Langmuir turbulence as represented in KPPLT-VR12 and KPPLT-LF17 in these test cases are most important during periods when the mixed layer is deepening. Such effects on the simulated SST, SSS, and MLD in a single-column setup can sometimes be comparable to the effects of the missing advection and lateral processes at Ocean Station Papa (inferred from the mismatch between modeled and observed data). The magnitude of such effects also appears to be comparable to or even larger than the effects of tidal forcing in the northern North Sea in the FLEX case. These results highlight the importance of correctly representing the effects of Langmuir turbulence in an ocean vertical mixing scheme. Compared with the $k-\varepsilon$ scheme, all three variants of KPP suffer from much higher sensitivity to the vertical resolution, consistent with previous studies (e.g., Van Roekel et al., 2018; Li et al., 2019), but lower sensitivity to the time step.

The newly developed YAML-based configuration in GOTM also enables an easier GOTM workflow using Python and Jupyter notebook, both gaining popularity rapidly over the years in the broader scientific community. This provides an interface to use GOTM interactively in the Jupyter notebook environment, especially as a single-water-column model which has been extremely useful in both parameterization development and evaluation (e.g., Burchard and Bolding, 2001; Burchard et al., 2008; Reichl et al., 2016; Li et al., 2019) and parameter space exploration (e.g., Li et al., 2019; Dong et al., 2020). As an example, all the simulations and figures in this paper are conducted and produced in the Jupyter notebook environment using this new workflow. Both the source code for this new workflow and the Jupyter notebooks for this paper are available online for maximum reproducibility (see the Code and data availability section below for more details).

This study represents the initial steps extending the capability of GOTM to include Langmuir turbulence parameterizations, although we note that GOTM has already been used in previous studies in developing and evaluating Langmuir turbulence parameterizations (e.g., Reichl et al., 2016; Li et al., 2019). Even though only a limited set of KPP variants is included, the development here facilitates future incorporation of second-moment closure schemes of Langmuir turbulence (e.g., Harcourt, 2013, 2015), as well as the development and evaluation of new Langmuir turbulence parameterizations in the GOTM framework. The Python- and Jupyternotebook-based GOTM workflow enabled by the YAMLbased configuration also makes future applications of GOTM easier.

It should be noted that GOTM can also be coupled to the frequently used Framework for Aquatic Biogeochemical
Models (FABM, Bruggeman and Bolding, 2014) to study the evolution of marine ecosystems. The effect of different turbulence models for ecosystem-related questions can now be evaluated within a single modeling framework. However, a systematic evaluation of such effect is beyond the scope of this work and is left for future study.

Code and data availability. The source code of GOTM (v6.0) is available at https://doi.org/10.5281/zenodo.4896611 (Bolding et al., 2021). The Python tools for the new workflow are available at https://doi.org/10.5281/zenodo.4892158 (Li, 2021a). The Jupyter notebooks and data to run the GOTM simulations and to reproduce the figures are available at https://doi.org/10.5281/zenodo.4892159 (Li, 2021b).

Author contributions. QL and $\mathrm{KB}$ implemented the CVMix and Stokes drift modules in GOTM. JB and KB developed the YAMLbased configuration in GOTM. QL developed the Python tools for GOTM. QL conducted the GOTM simulations and analyses with help and guidance from HB and LU. QL led the writing of this manuscript with contributions from all authors at all stages.

Competing interests. The authors declare that they have no conflict of interest.

Disclaimer. Publisher's note: Copernicus Publications remains neutral with regard to jurisdictional claims in published maps and institutional affiliations.

Acknowledgements. We sincerely thank two anonymous reviewers for their very helpful input on this article. We thank Ulf Gräwe at Leibniz Institute for Baltic Sea Research Warnemünde for providing the meteorological and wave data for the Gotland Basin case.

Financial support. Qing $\mathrm{Li}$ is supported by the Earth System Model Development program area of the US Department of Energy, Office of Science, Office of Biological and Environmental Research as part of the multi-program, collaborative Integrated Coastal Modeling (ICoM) project. Lars Umlauf is supported by the German Research Foundation (DFG) for subproject L4 ("Energyconsistent atmosphere ocean coupling"), embedded in the Collaborative Research Centre TRR 181 "Energy Transfers in Atmosphere and Ocean". Knut Klingbeil and Hans Burchard are supported by TRR 181 as well. This project also funded parts of the integration of CVMix into GOTM carried out by Karsten Bolding and Jorn Bruggeman, who received further support from IOW to improve the YAML-based GOTM configurations.

Review statement. This paper was edited by Qiang Wang and reviewed by two anonymous referees. 


\section{References}

Acreman, D. and Jeffery, C.: The Use of Argo for Validation and Tuning of Mixed Layer Models, Ocean Model., 19, 53-69, https://doi.org/10.1016/j.ocemod.2007.06.005, 2007.

Arneborg, L., Fiekas, V., Umlauf, L., and Burchard, H.: Gravity current dynamics and entrainment - a process study based on observations in the Arkona Basin, J. Phys. Oceanogr., 37, 2094-2113, 2007

Axell, L. B.: Wind-Driven Internal Waves and Langmuir Circulations in a Numerical Ocean Model of the Southern Baltic Sea, J. Geophys. Res., 107, 3204, https://doi.org/10.1029/2001JC000922, 2002.

Bolding, K., Bruggeman, J., Burchard, H., and Umlauf, L.: General Ocean Turbulence Model - GOTM (Version v6.0.2), Zenodo, https://doi.org/10.5281/zenodo.4896611, 2021,

Bollmeyer, C., Keller, J. D., Ohlwein, C., Wahl, S., Crewell, S., Friederichs, P., Hense, A., Keune, J., Kneifel, S., Pscheidt, I., Redl, S., and Steinke, S.: Towards a High-Resolution Regional Reanalysis for the European CORDEX Domain, Q. J. Roy. Meteor. Soc., 141, 1-15, https://doi.org/10.1002/qj.2486, 2015.

Breivik, Ø., Bidlot, J.-R., and Janssen, P. A. E. M.: A Stokes Drift Approximation Based on the Phillips Spectrum, Ocean Model., 100, 49-56, https://doi.org/10.1016/j.ocemod.2016.01.005, 2016.

Bruggeman, J. and Bolding, K.: A General Framework for Aquatic Biogeochemical Models, Environ. Model. Softw., 61, 249-265, https://doi.org/10.1016/j.envsoft.2014.04.002, 2014.

Burchard, H. and Baumert, H.: On the performance of a mixed-layer model based on the $k-\varepsilon$ turbulence closure, J. Geophys. Res., 100, 8523-8540, 1995.

Burchard, H. and Bolding, K.: Comparative Analysis of Four Second-Moment Turbulence Closure Models for the Oceanic Mixed Layer, J. Phys. Oceanogr., 31, 1943-1968, https://doi.org/10.1175/15200485(2001)031<1943:CAOFSM>2.0.CO;2, 2001.

Burchard, H. and Bolding, K.: GETM - a general estuarine transport model, Scientific Documentation, Tech. Rep. EUR 20253 EN, European Commission, 2002.

Burchard, H., Bolding, K., and Villarreal, M. R.: GOTM - a general ocean turbulence model. Theory, applications and test cases, Tech. Rep. EUR 18745 EN, European Commission, 1999.

Burchard, H., Bolding, K., Kühn, W., Meister, A., Neumann, T., and Umlauf, L.: Description of a Flexible and Extendable Physical - Biogeochemical Model System for the Water Column, J. Marine Syst., 61, 180-211, https://doi.org/10.1016/j.jmarsys.2005.04.011, 2006.

Burchard, H., Craig, P. D., Gemmrich, J. R., van Haren, H., Mathieu, P.-P., Meier, H. E. M., Smith, W. A. M. N., Prandke, H., Rippeth, T. P., Skyllingstad, E. D., Smyth, W. D., Welsh, D. J. S., and Wijesekera, H. W.: Observational and Numerical Modeling Methods for Quantifying Coastal Ocean Turbulence and Mixing, Prog. Oceanogr., 76, 399-442, https://doi.org/10.1016/j.pocean.2007.09.005, 2008.

Burchard, H., Schuttelaars, H. M., and Geyer, W. R.: Residual sediment fluxes in weakly-to-periodically stratified estuaries and Tidal Inlets, J. Phys. Oceanogr., 43, 1841-1861, 2013.

Canuto, V. M., Howard, A., Cheng, Y., and Dubovikov, M. S.: Ocean Turbulence. Part I: One-Point Closure Model - Momentum and Heat Vertical Diffusivities, J. Phys.
Oceanogr., 31, 1413-1426, https://doi.org/10.1175/15200485(2001)031<1413:OTPIOP>2.0.CO;2, 2001.

Chen, C., Liu, H., and Beardsley, R. C.: An unstructured grid, finitevolume, three-dimensional, primitive equations ocean model: application to coastal ocean and estuaries, J. Atmos. Ocean. Tech., 20, 159-186, 2003.

Conley, D. C., Falchetti, S., Lohmann, I. P., and Brocchini, M.: The effects of flow stratification by non-cohesive sediment on transport in high-energy wave-driven flows, J. Fluid Mech., 610, 4367, 2008.

D'Alessio, S. J. D., Abdella, K., and McFarlane, N. A.: A New Second-Order Turbulence Closure Scheme for Modeling the Oceanic Mixed Layer, J. Phys. Oceanogr., 28, 1624-1641, https://doi.org/10.1175/15200485(1998)028<1624:ANSOTC>2.0.CO;2, 1998.

Danabasoglu, G., Large, W. G., Tribbia, J. J., Gent, P. R., Briegleb, B. P., and McWilliams, J. C.: Diurnal Coupling in the Tropical Oceans of CCSM3, J. Climate, 19, 2347-2365, https://doi.org/10.1175/JCLI3739.1, 2006.

de Boyer Montégut, C., Madec, C., Fischer, A. S., Lazar, A., and Iudicone, D.: Mixed Layer Depth over the Global Ocean: An Examination of Profile Data and a ProfileBased Climatology, J. Geophys. Res., 109, C12003, https://doi.org/10.1029/2004JC002378, 2004.

Dong, J., Fox-Kemper, B., Zhang, H., and Dong, C.: The Scale of Submesoscale Baroclinic Instability Globally, J. Phys. Oceanogr., 50, 2649-2667, https://doi.org/10.1175/JPO-D-200043.1, 2020.

Durski, S. M., Glenn, S. M., and Haidvogel, D. B.: Vertical Mixing Schemes in the Coastal Ocean: Comparison of the Level 2.5 Mellor-Yamada Scheme with an Enhanced Version of the K Profile Parameterization, J. Geophys. Res.-Oceans, 109, C01015, https://doi.org/10.1029/2002JC001702, 2004.

Fairall, C. W., Bradley, E. F., Rogers, D. P., Edson, J. B., and Young, G. S.: Bulk Parameterization of Air-Sea Fluxes for Tropical Ocean-Global Atmosphere Coupled-Ocean Atmosphere Response Experiment, J. Geophys. Res.-Oceans, 101, 3747-3764, https://doi.org/10.1029/95JC03205, 1996.

Feistel, R., Nausch, G., and Wasmund, N. (Eds.): State and Evolution of the Baltic Sea, 1952-2005. A Detailed 50-Year Survey of Meteorology and Climate, Physics, Chemistry, Biology, and Marine Environment, Wiley-Interscience, Hoboken, NJ, USA, 2008.

Frey, H.: A three-dimensional, baroclinic shelf sea circulation model - 1 . The turbulence closure scheme and the onedimensional test model, Cont. Shelf Res., 11, 365-395, 1991.

Friedrich, H.: Simulation of the thermal stratification at the FLEX central station with a one-dimensional integral model, in: North Sea Dynamics, Springer, Berlin, Heidelberg, 396-411, 1983.

Grant, A. L. M. and Belcher, S. E.: Characteristics of Langmuir Turbulence in the Ocean Mixed Layer, J. Phys. Oceanogr., 39, 1871-1887, https://doi.org/10.1175/2009JPO4119.1, 2009.

Griffies, S. M., Levy, M., Adcroft, A. J., Danabasoglu, G., Hallberg, R. W., Jacobsen, D., Large, W., and Ringler, T.: Theory and Numerics of the Community Ocean Vertical Mixing (CVMix) Project, Tech. rep., 2015.

Haidvogel, D. B., Arango, H. G., Hedstrom, K., Beckmann, A., Malanotte-Rizzoli, P., and Shchepetkin, A. F.: Model evaluation experiments in the North Atlantic Basin: simulations in nonlin- 
ear terrain-following coordinates, Dynam. Atmos. Oceans, 32, 239-281, 2000.

Harcourt, R. R.: A Second-Moment Closure Model of Langmuir Turbulence, J. Phys. Oceanogr., 43, 673-697, https://doi.org/10.1175/JPO-D-12-0105.1, 2013.

Harcourt, R. R.: An Improved Second-Moment Closure Model of Langmuir Turbulence, J. Phys. Oceanogr., 45, 84-103, https://doi.org/10.1175/JPO-D-14-0046.1, 2015.

Harcourt, R. R. and D'Asaro, E. A.: Large-Eddy Simulation of Langmuir Turbulence in Pure Wind Seas, J. Phys. Oceanogr., 38, 1542-1562, https://doi.org/10.1175/2007JPO3842.1, 2008.

Hense, I. and Quack, B.: Modelling the vertical distribution of bromoform in the upper water column of the tropical Atlantic Ocean, Biogeosciences, 6, 535-544, https://doi.org/10.5194/bg-6-5352009, 2009.

Holt, J. and Umlauf, L.: Modelling the Tidal Mixing Fronts and Seasonal Stratification of the Northwest European Continental Shelf, Cont. Shelf Res., 28, 887-903, https://doi.org/10.1016/j.csr.2008.01.012, 2008.

Holtermann, P., Burchard, H., Gräwe, U., Klingbeil, K., and Umlauf, L.: Deep-Water Dynamics and Boundary Mixing in a Non-Tidal Stratified Basin. A Modeling Study of Baltic Sea, J. Geophys. Res.-Oceans, 119, 1465-1487, https://doi.org/10.1002/2013JC009483, 2014.

Jones, N. L. and Monismith, S. G.: The influence of whitecapping waves on the vertical structure of turbulence in a shallow estuarine embayment, J. Phys. Oceanogr., 38, 1563-1580, 2008.

Kantha, L. H. and Clayson, C. A.: An Improved Mixed Layer Model for Geophysical Applications, J. Geophys. Res., 99, 2523525266, https://doi.org/10.1029/94JC02257, 1994.

Kantha, L. H. and Clayson, C. A.: On the Effect of Surface Gravity Waves on Mixing in the Oceanic Mixed Layer, Ocean Model., 6, 101-124, https://doi.org/10.1016/S14635003(02)00062-8, 2004

Kerimoglu, O., Jacquet, S., Vinçon-Leite, B., Lemaire, B. J., Rimet, F., Soulignac, F., Trevisan, D., and Anneville, O.: Modelling the plankton groups of the deep, peri-alpine Lake Bourget, Ecol. Modell., 359, 415-433, 2017.

Large, W. G.: An Observational and Numerical Investigation of the Climatological Heat and Salt Balances at OWS Papa, J. Climate, 9, 1856-1876, https://doi.org/10.1175/15200442(1996)009<1856:AOANIO>2.0.CO;2, 1996.

Large, W. G., Mcwilliams, J. C., and Doney, S. C.: Oceanic Vertical Mixing: A Review and a Model with a Nonlocal Boundary Layer Parameterization, Rev. Geophys., 32, 363-403, https://doi.org/10.1029/94RG01872, 1994.

Li, Q.: qingli411/gotmtool: Update GOTM output config (Version v1.1.1), Zenodo, https://doi.org/10.5281/zenodo.4892158, 2021a.

Li, Q.: qingli411/A2020_CVMix_in_GOTM: Update GOTM output config (Version v1.1.1), Zenodo, https://doi.org/10.5281/zenodo.4892159, 2021b.

Li, Q. and Fox-Kemper, B.: Assessing the Effects of Langmuir Turbulence on the Entrainment Buoyancy Flux in the Ocean Surface Boundary Layer, J. Phys. Oceanogr., 47, 2863-2886, https://doi.org/10.1175/JPO-D-17-0085.1, 2017.

Li, Q., Webb, A., Fox-Kemper, B., Craig, A., Danabasoglu, G., Large, W. G., and Vertenstein, M.: Langmuir Mixing Effects on Global Climate: WAVEWATCH III in CESM, Ocean Model.,
103, 145-160, https://doi.org/10.1016/j.ocemod.2015.07.020 2016.

Li, Q., Fox-Kemper, B., Breivik, Ø., and Webb, A.: Statistical Models of Global Langmuir Mixing, Ocean Model., 113, 95-114, https://doi.org/10.1016/j.ocemod.2017.03.016, 2017.

Li, Q., Reichl, B. G., Fox-Kemper, B., Adcroft, A., Belcher, S., Danabasoglu, G., Grant, A., Griffies, S. M., Hallberg, R. W., Hara, T., Harcourt, R., Kukulka, T., Large, W. G., McWilliams, J. C., Pearson, B., Sullivan, P., Van Roekel, L., Wang, P., and Zheng, Z.: Comparing Ocean Surface Boundary Vertical Mixing Schemes Including Langmuir Turbulence, J. Adv. Model. Earth Sy., 11, 3545-3592, https://doi.org/10.1029/2019MS001810, 2019.

Madec, G., Delecluse, P., Crepon, M., and Chartier, M.: A threedimensional numerical study of deep-water formation in the northwestern Mediterranean Sea, J. Phys. Oceanogr., 21, 1349$1371,1991$.

Martin, P. J.: Simulation of the mixed layer at OWS November and Papa with several models, J. Geophys. Res., 90, 903-916, 1985.

McWilliams, J. C., Sullivan, P. P., and Moeng, C.-H.: Langmuir Turbulence in the Ocean, J. Fluid Mech., 334, 1-30, https://doi.org/10.1017/S0022112096004375, 1997.

Paulson, C. A. and Simpson, J. J.: Irradiance Measurements in the Upper Ocean, J. Phys. Oceanogr., 7, 952-956, https://doi.org/10.1175/15200485(1977)007<0952:IMITUO>2.0.CO;2, 1977.

Powley, H. R., Bruggeman, J., Hopkins, J., Smyth, T., and Blackford, J.: Sensitivity of shelf sea marine ecosystems to temporal resolution of meteorological forcing, J. Geophys. Res.-Oceans, 127, e2019JC015922, https://doi.org/10.1029/2019JC015922, 2020.

Price, J. F.: On the Scaling of Stress-Driven Entrainment Experiments, J. Fluid Mech., 90, 509-529, https://doi.org/10.1017/S0022112079002366, 1979.

Reichl, B. G. and Hallberg, R.: A Simplified Energetics Based Planetary Boundary Layer (ePBL) Approach for Ocean Climate Simulations, Ocean Model., 132, 112-129, https://doi.org/10.1016/j.ocemod.2018.10.004, 2018.

Reichl, B. G. and Li, Q.: A Parameterization with a Constrained Potential Energy Conversion Rate of Vertical Mixing Due to Langmuir Turbulence, J. Phys. Oceanogr., 49, 2935-2959, https://doi.org/10.1175/JPO-D-18-0258.1, 2019.

Reichl, B. G., Wang, D., Hara, T., Ginis, I., and Kukulka, T.: Langmuir Turbulence Parameterization in Tropical Cyclone Conditions, J. Phys. Oceanogr., 46, 863-886, https://doi.org/10.1175/JPO-D-15-0106.1, 2016.

Soetje, K. C. and Huber, K.: A compilation of data on the thermal stratification at the central station in the northern North Sea during FLEX'76, Meteor-Forsch.-Ergebnisse Reihe A, 22, 69-77, 1980.

Steiner, N., Vagle, S., Denman, K., and McNeil, C.: Oxygen and nitrogen cycling in the northeast Pacific-Simulations and observations at Station Papa in 2003/2004, J. Mar. Res., 65, 441-469, 2007.

Thomson, J., D’Asaro, E. A., Cronin, M. F., Rogers, W. E., Harcourt, R. R., and Shcherbina, A.: Waves and the Equilibrium Range at Ocean Weather Station P, J. Geophys. Res.-Oceans, 118, 5951-5962, https://doi.org/10.1002/2013JC008837, 2013. 
Umlauf, L. and Burchard, H.: A Generic Length-Scale Equation for Geophysical Turbulence Models, J. Mar. Res., 61, 235-265, https://doi.org/10.1357/002224003322005087, 2003.

Umlauf, L. and Burchard, H.: Second-Order Turbulence Closure Models for Geophysical Boundary Layers. A Review of Recent Work, Cont. Shelf Res., 25, 795-827, https://doi.org/10.1016/j.csr.2004.08.004, 2005.

Umlauf, L. and Burchard, H.: Diapycnal Transport and Mixing Efficiency in Stratified Boundary Layers near Sloping Topography, J. Phys. Oceanogr., 41, 329-345, https://doi.org/10.1175/2010JPO4438.1, 2010.

Umlauf, L., Burchard, H., and Bolding, K.: GOTM Sourcecode and Test Case Documentation, Tech. rep., 2014.

Umlauf, L., Smyth, W. D., and Moum, J. N.: Energetics of Bottom Ekman Layers during Buoyancy Arrest, J. Phys. Oceanogr., 45, 3099-3117, https://doi.org/10.1175/JPO-D-15-0041.1, 2015.

van den Bremer, T. S. and Breivik, Ø.: Stokes Drift, Philos. T. R. Soc. A, 376, 20170104, https://doi.org/10.1098/rsta.2017.0104, 2018.

van der Molen, J., Aldridge, J. N., Coughlan, C., Parker, E. R., Stephens, D., and Ruardij, P.: Modelling marine ecosystem response to climate change and trawling in the North Sea, Biogeochemistry, 113, 213-236, 2013.
Van Roekel, L., Fox-Kemper, B., Sullivan, P. P., Hamlington, P. E., and Haney, S. R.: The Form and Orientation of Langmuir Cells for Misaligned Winds and Waves, J. Geophys. Res., 117, C05001, https://doi.org/10.1029/2011JC007516, 2012.

Van Roekel, L., Adcroft, A., Danabasoglu, G., Griffies, S. M., Kauffman, B., Large, W., Levy, M., Reichl, B. G., Ringler, T., and Schmidt, M.: The KPP Boundary Layer Scheme for the Ocean: Revisiting Its Formulation and Benchmarking One-Dimensional Simulations Relative to LES, J. Adv. Model. Earth Sy., 10, 26472685, https://doi.org/10.1029/2018MS001336, 2018.

Webb, A. and Fox-Kemper, B.: Wave Spectral Moments and Stokes Drift Estimation, Ocean Modelling, 40, 273-288, https://doi.org/10.1016/j.ocemod.2011.08.007, 2011.

Webb, A. and Fox-Kemper, B.: Impacts of Wave Spreading and Multidirectional Waves on Estimating Stokes Drift, Ocean Model., 96, 49-64, https://doi.org/10.1016/j.ocemod.2014.12.007, 2015.

Zhang, Y. J., Ye, F., Stanev, E. V., and Grashorn, S.: Seamless crossscale modeling with SCHISM, Ocean Model., 102, 64-81, 2016. 